\title{
Leveraging the interplay between homogeneous and heterogeneous catalytic mechanisms: copper-iron nanoparticles working under chemically relevant tumor conditions
}

Javier Bonet-Aleta ${ }^{a, b, c}$, Miguel Encinas ${ }^{a, b, c}$, Esteban Urriolabeitia ${ }^{d}$, Pilar Martin-Duque ${ }^{b, e, f, g}$, Jose L. Hueso $^{\mathrm{a}, \mathrm{b}, \mathrm{c}}$, Jesus Santamaria $\mathrm{a}, \mathrm{b}, \mathrm{c}, \mathrm{f}$

anstitute of Nanoscience and Materials of Aragon (INMA), CSIC-Universidad de Zaragoza, Campus Río Ebro, Edificio I+D, C/ Poeta Mariano Esquillor, s/n, 50018, Zaragoza, Spain.

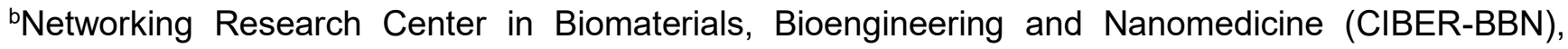
Madrid, Spain. Instituto de Salud Carlos III; 28029, Madrid, Spain.

'Department of Chemical and Environmental Engineering; University of Zaragoza, Spain; Campus Rio Ebro, C/María de Luna, 3, 50018 Zaragoza, Spain.

IInstituto de Síntesis Química y Catálisis Homogénea, ISQCH (CSIC-Universidad de Zaragoza), 50009 Zaragoza, Spain.

eInstituto Aragonés de Ciencias de la Salud (IACS), Avenida San Juan Bosco, 13, 50009 Zaragoza, Spain.

fInstituto de Investigación Sanitaria (IIS) Aragón, Avenida San Juan Bosco, 13, 50009 Zaragoza, Spain.

gFundación Araid. Av. de Ranillas 1-D, 50018 Zaragoza, Spain. 


\begin{abstract}
The present work sheds light on a generally overlooked issue in the emerging field of bio-orthogonal catalysis within tumor microenvironments (TMEs): the interplay between homogeneous and heterogeneous catalytic processes. In most cases, previous works dealing with nanoparticle-based catalysis in the TME, focus on the effects obtained (e.g. tumor cell death) and attribute the results to heterogeneous processes alone. The specific mechanisms are rarely substantiated and, furthermore, the possibility of a significant contribution of homogeneous processes by leached species -and the complexes that they may form with biomolecules- is neither contemplated nor pursued. Herein, we have designed a bimetallic catalyst nanoparticle containing $\mathrm{Cu}$ and $\mathrm{Fe}$ species and we have been able to describe the whole picture in a more complex scenario where both homogeneous and heterogeneous processes are coupled and fostered under TME relevant chemical conditions. We investigate the preferential leaching of $\mathrm{Cu}$ ions in the presence of a TME overexpressed biomolecule such as glutathione (GSH). We demonstrate that these homogeneous processes initiated by the released by $\mathrm{Cu}-\mathrm{GSH}$ interactions are in fact responsible for the greater part of the cell death effects found (GSH, a scavenger of reactive oxygen species is depleted and highly active superoxide anions are generated in the same catalytic cycle). The remaining solid CuFe nanoparticle becomes an active catalase-mimicking surrogate able to supply oxygen from oxygen reduced species, such as superoxide anions (by-product from GSH oxidation) and hydrogen peroxide, another species that is enriched in the TME. This enzyme-like activity is essential to sustain the homogeneous catalytic cycle in the oxygen-deprived tumor microenvironment. The combined heterogeneous-homogeneous mechanisms revealed themselves as highly efficient in selectively killing cancer cells, due to their higher GSH levels compared to healthy cell lines.
\end{abstract}


Glutathione (GSH) is a key peptide in the regulation of intracellular Reactive Oxygen Species (ROS) levels. Its role is of paramount importance in the tumor microenvironment (TME) ${ }^{1}$, where GSH is overexpressed to counteract the overproduction of oxidizing species such as $\mathrm{H}_{2} \mathrm{O}_{2}$ that may disrupt redox homeostasis leading to apoptosis ${ }^{2}$. GSH counteracts the generation of ROS via enzymatic reaction with the Glutathione Peroxidase (GPx) enzyme ${ }^{3}$. Consequently, GSH is quickly becoming the target of new cancer therapies ${ }^{1}$. In addition, the high intratumoral GSH concentrations (up to $\mathrm{mM}^{4,5}$ ) may interfere with emerging cancer therapies (Chemodynamic- (CDT), Sonodynamic- (SDT), and Photodynamic (PDT)) therapy that are ROS-dependent and become less effective in the presence of increased GSH levels ${ }^{6}$.

Nanocatalytic cancer therapy is rapidly emerging as a novel alternative able to trigger selective catalytic reactions in cancer cells to induce their apoptosis ${ }^{7,8}$. Transition metal nanocatalysts in particular are able to promote GSH depletion via oxidation mechanisms thereby interfering in the survival and protection mechanisms of cancer cells ${ }^{7}$. The ideal scenario involves catalytic materials that can eliminate antioxidant molecules such as $\mathrm{GSH}$, while simultaneously promoting the generation of ROS. It is obvious that a deeper understanding of the role of nanocatalysts in the TME is critical to enhance their efficient action. However, this still represents a formidable challenge: the catalytic mechanisms of the most promising nanoplatforms and their interplay with key biomolecules remains elusive due to the complexity of the interactions in the TME.

A fundamental aspect of the interaction between catalyst nanoparticles and the TME that is often overlooked relates to the surface phenomena involved. In particular, leaching (i.e. metal ions lixiviated from the surface of the nanostructured catalysts into the surrounding fluid) is a phenomenon likely to have a strong influence on the final therapy outcome. Previous investigations have aimed at designing nanoplatforms with $\mathrm{pH}$-triggered metal ion lixiviation given the mildly-acidic $\mathrm{TME}^{9}$. The influence of acidity in metal lixiviation has been explored in several cancer-related works for Fe ${ }^{10,11}$, $\mathrm{Mn}^{12-14}$ or $\mathrm{Cu}^{15-20}$. It has also been shown that the complex chemical composition in biological environments includes molecular species such as aminoacids, that may promote lixiviation especially in the case of $\mathrm{Cu}^{21-23}$. However, the role that these species may play as catalysts and the interactions with heterogeneous processes fostered by the solid phase have not been investigated.

Some valuable insights can be derived from conventional, aqueous phase catalysis. Eremin et al. ${ }^{24}$ recently pictured an expanded vision of the nature of transition-metal-catalyzed reactions. These authors described the well-established scenarios of (i) Molecular-based Catalysis and (ii) Nanoparticle-based Catalysis (heterogeneous catalysis) and presented a perspective of three additional intermediate scenarios given by (iii) Lixiviation-driven catalysis; (iv) "Cocktail" of catalysts derived from the nanoparticle (clusters, atoms, lixiviated ions) and (v) Dynamic catalytic systems. The 
action of the catalyst nanoparticles used in medical applications is generally interpreted on the premises of purely heterogeneous mechanisms. Only in a few cases, (e.g. $\mathrm{MnO}_{2}$-based nanomaterials, where dissolution of the nano-oxide structure through reaction with GSH is followed by Fenton processes facilitated by the as-formed $\mathrm{Mn}^{2+}$ ions) an attempt has been made to describe processes closer to lixiviation-driven catalysis. It must be noticed that the nanoplatforms evaluated as catalysts for cancer therapy are usually composed by more than one metal, (e.g. $\mathrm{Cu}_{2} \mathrm{MoS}_{4}{ }^{25}$, $\mathrm{MnFe}_{2} \mathrm{O}_{4}{ }^{26}, \mathrm{CuFe}_{2} \mathrm{O}_{4}{ }^{27}$, Copper/Manganese silicate ${ }^{17}, \mathrm{Cu}_{x} \mathrm{Fe}_{\mathrm{y}} \mathrm{S}_{\mathrm{z}}{ }^{28}$ or $\mathrm{SrCuSi}_{4} \mathrm{O}_{10}{ }^{20}$ ) and these may be affected to a different extent by lixiviation phenomena under the mildly-acidic, hypoxic and GSHenriched conditions prevalent in the TME. In any case, issues such as the extent of the lixiviation process, the possibility of a preferential leaching of a specific transition metal or the influence of specific chemical species present in the TME remain mostly unexplored. At present, is not possible to state whether the therapeutic action of nanocatalysts in the TME is attributable to lixiviated ions, a purely heterogeneous reaction, or a combination of both phenomena.

Here, we have thoroughly evaluated the catalytic mechanisms behind the action of a copper-iron mixed oxide (CuFe) nanocatalyst under representative conditions for a TME. This is a bimetallic system, complex enough to illustrate the main phenomena taking place. Our results shed light on the interplay between heterogeneous and homogeneous processes occurring in the presence of GSH. We report for the first time how the presence of elevated levels of $\mathrm{GSH}$ induces a preferential lixiviation of $\mathrm{Cu}$ species, initiating a homogeneous catalytic cycle that efficiently oxidizes GSH into Glutathione Disulfide (GSSG), assisted by the in situ formation of Cu-GSH coordination complexes. Simultaneously, the progressively Fe-enriched NP gives rise to heterogeneous catalytic cycles using ROS generated in the homogeneous GSH oxidation cycle (Fig. 1) or the overexpressed $\mathrm{H}_{2} \mathrm{O}_{2}$ present in the tumoral media ${ }^{29,30}$. The system chosen is of especial interest, considering the increasing relevance of $\mathrm{Cu}$ and its interaction with key processes in cancer development ${ }^{31}$. Overall, the results presented in this work provide new insight on the dynamics of the chemical reactions inside the TME and valuable clues for the design of more efficient catalysts to operate in this environment. 


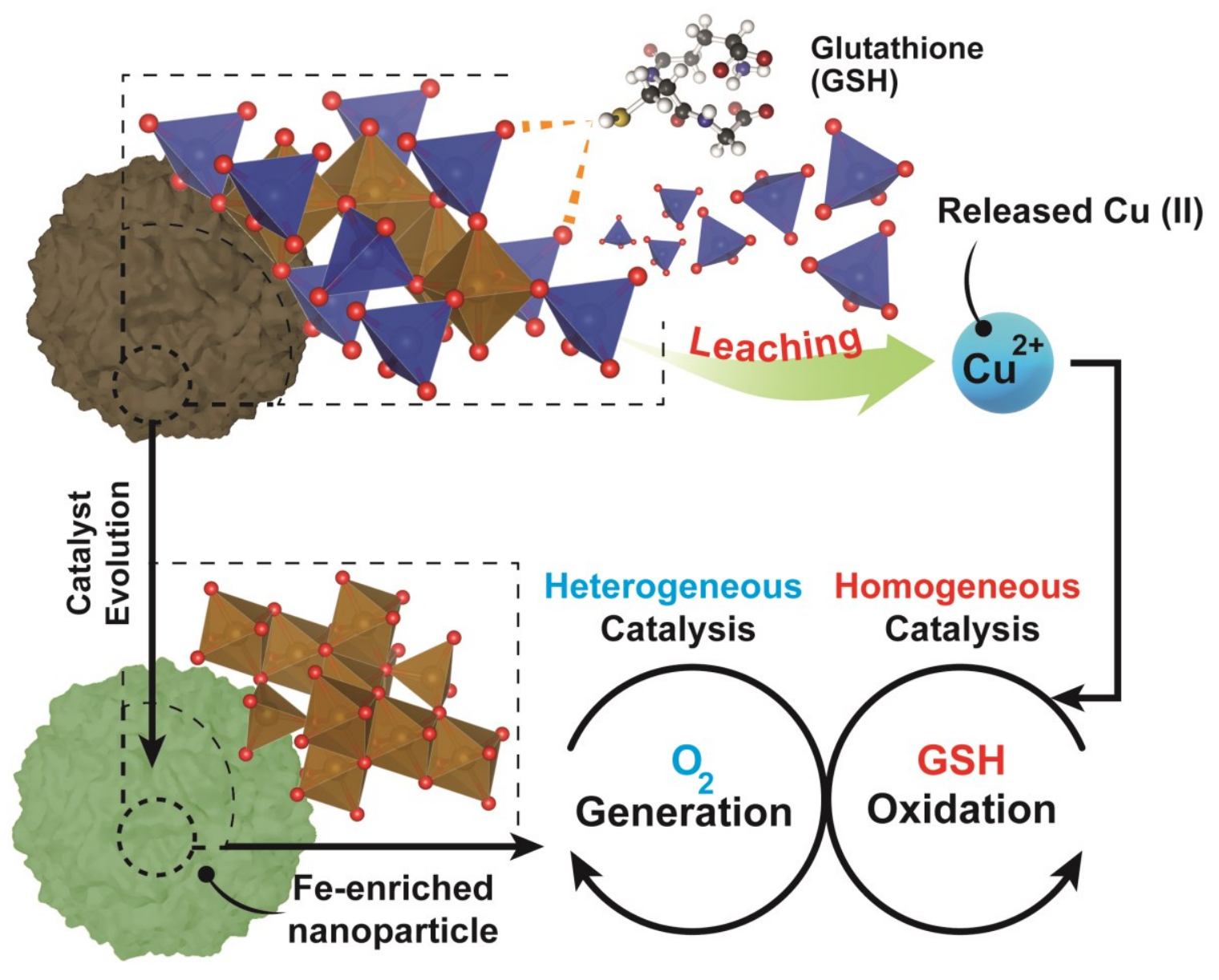

Fig. 1. Simplified overview of the homogeneous-heterogeneous processes fostered by the CuFe nanocatalyst in the presence of GSH. After a GSH-triggered $\mathrm{Cu}$ release from the nanocatalyst, $\mathrm{Cu}^{2+}$ catalyze the homogeneous oxidation of GSH into GSSG. Simultaneously, $\mathrm{Fe}(\mathrm{III})$ species present on the nanoparticle surface catalyze the conversion of $\mathrm{H}_{2} \mathrm{O}_{2}$ and $\cdot \mathrm{O}_{2}{ }^{-}$species, considered as by-products from $\mathrm{GSH}$ oxidation into $\mathrm{O}_{2}$ necessary to sustain the $\mathrm{GSH}$ depletion homogeneous cycle. 


\section{RESULTS}

Cation leaching in the presence of GSH. The influence of GSH on the release of ionic $\mathrm{Cu}$ and $\mathrm{Fe}$ from the $\mathrm{CuFe}_{2} \mathrm{O}_{4}$ nanocatalyst was quantified by Microwave Plasma -Atomic Emission Spectroscopy (see Experimental section for details). The presence of $\mathrm{GSH}$ at a concentration of $5 \mathrm{mM}$ changed considerably the leaching patterns. Thus, the release of $\mathrm{Cu}$ was strongly enhanced, with a cumulative release of ca. $70 \%$ of the initial $\mathrm{Cu}$ in the particle after $24 \mathrm{~h}$ (compared to about $20 \%$ in the absence of $\mathrm{GSH}$ ). On the other hand, while $\mathrm{Fe}$ is not expected to be lixiviated significantly at this $\mathrm{pH}$, we found that ca. $30 \%$ of the initial Fe content was released from the nanoparticle after $24 \mathrm{~h}$ (see Fig. 2a). We attribute this behavior to the generation of high-energy vacancies after GSH-triggered Cu release that facilitates the transfer of $\mathrm{Fe}$ into the solution ${ }^{32}$. The fact that $\mathrm{Cu}$ release is favored in the presence of GSH can be anticipated since previous works had reported $\mathrm{Cu}$ lixiviation from $\mathrm{CuO}$ nanoparticles in the presence of aminoacids or peptides ${ }^{21,22}$. Interestingly, at lower $\mathrm{pH}$ values $(\mathrm{pH}$ of 5.80 , close to the $\mathrm{pH}$ in a solid tumor medium) the extent of leaching for both $\mathrm{Cu}$ and $\mathrm{Fe}$ in the presence of GSH was reduced (Fig. 2-b), although the percentage of $\mathrm{Cu}$ leached doubles that of iron. Considering the different ionic forms of GSH upon varying the $\mathrm{pH}^{33}$ (Fig. 2-c), this behavior can be linked to the stronger nucleophilic character of $-\mathrm{SH}$ group from $\mathrm{GSH}$ species as $\mathrm{pH}$ increases ${ }^{34}$. Compared to $-\mathrm{SH}$, thiolate $\left(-S^{-}\right)$form exhibits much stronger nucleophile behavior and the processes where $-S^{-}$is involved may occurs even at $\mathrm{pH}$ values far below thiol $\mathrm{pK}_{\mathrm{a}}{ }^{35}$, which may explain the promotion of $\mathrm{Cu}$ leaching at higher $\mathrm{pH}$. 

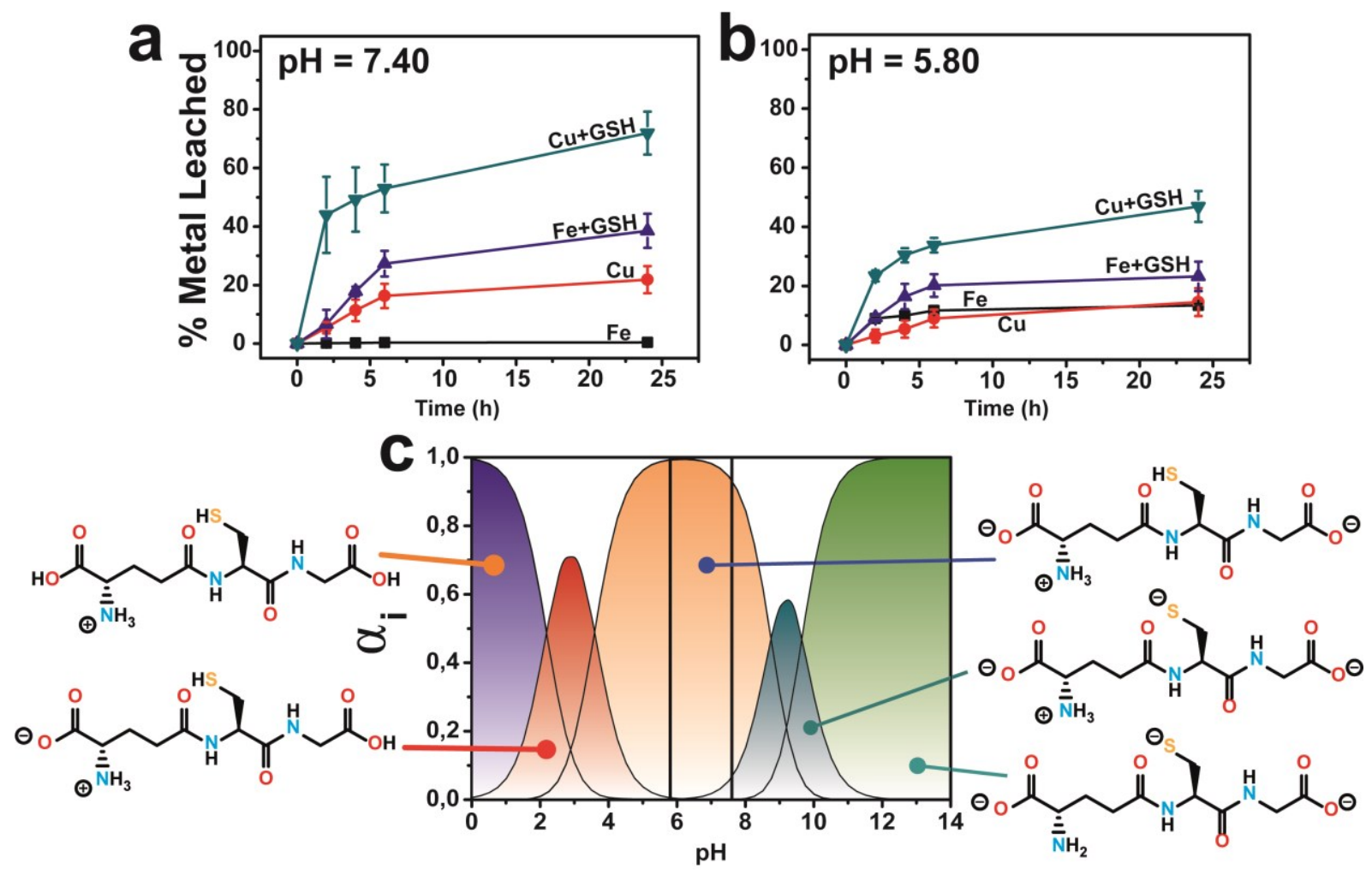

Fig. 2. GSH effect on the evolution of copper and iron cations lixiviated at different pH media:

(a) $\mathrm{pH}=7.4$; (b) $\mathrm{pH}=5.80$; (c) Different GSH ionic species as a function of different $\mathrm{pH}$ values; Vertical lines represent the $\mathrm{pH}$ of selected experimental conditions for a better identification of expected GSH species; GSH concentration was set to $5 \mathrm{mM}$. Speciation diagram was generated using $\mathrm{pK}_{\mathrm{a}}$ values obtained from $\left[{ }^{36}\right]$.

Homogeneous GSH oxidation by cations leached from CuFe nanoparticles. After the abrupt cation release observed in the presence of GSH (Fig 2. a-b) and its preferential action towards the lixiviation of $\mathrm{Cu}$ (roughly twice as much $\mathrm{Cu}$ is released, compared to $\mathrm{Fe}$ ), it is reasonable to assume a catalytic scenario mainly composed by aqueous $\mathrm{Cu}^{2+}$ ions and $\mathrm{GSH}(5 \mathrm{mM})$. This is relevant because previous works have described a evolution of GSH into its oxidized form (GSSG) catalyzed by $\mathrm{Cu}^{2+37}$. In this scenario, $\mathrm{O}_{2}$ could act as electron acceptor yielding reduced reactive oxygen species $\left(\cdot \mathrm{O}_{2}{ }^{-38,39}\right.$ and $\mathrm{H}_{2} \mathrm{O}_{2}{ }^{37}$ ) and GSSG as products, respectively (see Fig. 3a). Encouraged by these perspectives, we have explored the possibility of fostering homogeneous oxidation processes using the cations released from our $\mathrm{CuFe}_{2} \mathrm{O}_{4}$ nanocatalyst, while retaining the heterogeneous catalytic activity of the nanoparticles themselves.

In order to analyze the potential contribution of each lixiviated metal $(\mathrm{Fe}, \mathrm{Cu})$ in the homogeneous catalysis of $\mathrm{GSH}$ we performed a series of control experiments using chloride salt precursors $\left(\mathrm{CuCl}_{2}\right.$ and $\mathrm{FeCl}_{3}$, respectively). We carried out ${ }^{1} \mathrm{H}$-Nuclear Magnetic Resonance ( ${ }^{1} \mathrm{H}-\mathrm{NMR}$ ) analysis of the mixture $\mathrm{CuCl}_{2}+\mathrm{GSH}$ (Fig. 3b) to characterize the $\mathrm{Cu}(\mathrm{SG})_{2}$ complex ${ }^{39-43}$. These assays were 
performed in the absence of $\mathrm{O}_{2}$ to prevent the total evolution of the reaction to products. The resulting spectra revealed a splitting of the $\beta-\mathrm{CH}_{2}$ protons of the Cys residue of $\mathrm{GSH}$, appearing as an unresolved multiplet at $2.86 \mathrm{ppm}$ into a well defined $A B$ spin system at 3.22 and $2.88 \mathrm{ppm}$, due to the bonding of the $S$ atom to the reduced $\mathrm{Cu}(\mathrm{I})$ center $^{39,44}$. Other signals remained almost unchanged, suggesting that only the $S$ atom is involved in bonding of $\mathrm{GSH}$ to $\mathrm{Cu}(\mathrm{I})$. This is in accordance with Hard Soft Acid Base theory (HSAB), soft-basic thiol (-SH) groups from GSH tend to bond soft-acidic $\mathrm{Cu}(\mathrm{I})$ centers $^{45}$.

Diffusion-ordered NMR spectroscopy (DOSY) experiments were also performed with GSH, GSSG and the $\mathrm{CuCl}_{2}+\mathrm{GSH}$ binary mixture to determine the molecular size of each molecule and complex intermediates present in the solution based on their diffusion coefficients $\left(D, \mathrm{~m}^{2} \cdot \mathrm{s}^{-1}\right)$. The diffusion coefficients from the control experiments with GSH and GSSG (Fig. S1a-b) were adjusted to 3.98.1010 and $2.75 \cdot 10^{-10} \mathrm{~m}^{2} \cdot \mathrm{s}^{-1}$, respectively. Likewise, their corresponding hydrodynamic radii calculated through Stokes-Einstein equation were 0.6 and $0.9 \mathrm{~nm}$. These values are in good agreement with intramolecular distances obtained in X-ray structures for $\mathrm{GSH}^{46-48}$ and GSSG ${ }^{49,50}$. DOSY analysis of the $\mathrm{CuCl}_{2}+\mathrm{GSH}$ binary mixture yielded a product with a $\mathrm{D}=2.75 \cdot 10^{-10} \mathrm{~m}^{2} \cdot \mathrm{s}^{-1}$ (Fig. $32 \mathrm{a}$ ). In the presence of $\mathrm{Cu}^{2+}$, the species formed are larger than GSH (Fig. S1a) but of a similar size in comparison with GSSG (Fig. S1b). The complex $\mathrm{Cu}(\mathrm{SG})_{2}$ is formed under these conditions ${ }^{39-43}$, which exhibit a rather analogous coefficient D with respect to GSSG. Also, we were able to confirm the formation of the $\mathrm{Cu}$ complex through the homogeneous catalytic cycle of figure $3 a$ using High Resolution Mass Spectroscopy-ElectroSpray Ionization (HRMS-ESI) (Fig. 3c), that allowed identification of peaks corresponding to $[\mathrm{GSSG}+\mathrm{H}]^{+}(\mathrm{m} / \mathrm{z}=613.1613)$ and $\left[\mathrm{Cu}(\mathrm{SG})_{2}+\mathrm{H}\right]^{+}(\mathrm{m} / \mathrm{z}=$ 675.0801). Ngamchuea et al. ${ }^{37}$ studied the $\mathrm{Cu}(\mathrm{II})$-mediated $\mathrm{GSH}$ catalytic oxidation and suggested a reaction pathway based on kinetic experiments where $\mathrm{Cu}(\mathrm{SG})_{2}$, the same species detected in our control experiments (Fig. 3-c) also acted as reaction intermediate.

We also evaluated the potential contribution of Fe species to form complexes with GSH. In this case, control experiments with $\mathrm{FeCl}_{3}$ were carried out at $\mathrm{pH}=3.60$ to minimize the formation of iron hydroxide species which interfere with NMR measurements and the introduction of species that are not normally present at physiological $\mathrm{pH}$. ${ }^{1} \mathrm{H}-\mathrm{NMR}$ and DOSY control experiments with $\mathrm{FeCl}_{3}$ confirmed the formation of [Fe-(SG) $]$ complexes (Fig. S3a-b), with proton chemical shifts at 3.04 and $2.76 \mathrm{ppm}$ corresponding to assignments previously reported in the literature ${ }^{51,52}$. In addition, HRMSESI analysis revealed the formation of $\left[\mathrm{Fe}_{2}(\mathrm{SG})_{2}+\mathrm{H}\right]^{+}(\mathrm{m} / \mathrm{z}=725.0352)$ and $[\mathrm{Fe}(\mathrm{SG})+\mathrm{H}]^{+}(\mathrm{m} / \mathrm{z}=$ 363.0173) complexes (Fig. S4) $)^{51}$.

Once the formation of complexes with $\mathrm{Cu}$ and $\mathrm{Fe}$ cations were confirmed, analogous experiments with the CuFe nanocatalyst were subsequently carried out in the presence of GSH. The Cu lixiviated at $\mathrm{pH}=7.4$ interacted with the excess of GSH like in the control experiments. ${ }^{1} \mathrm{H}-\mathrm{NMR}$ and DOSY 
analysis of the solution (Fig. $\mathbf{3 b}$ and Fig. S2b), revealed both the presence of unreacted GSH $\left(D=4 \cdot 10^{-10} \mathrm{~m}^{2} \cdot \mathrm{s}^{-1}\right)$ and the formation of species with $D=2.70 \cdot 10^{-10} \mathrm{~m}^{2} \cdot \mathrm{s}^{-1}$. Taking into account the control experiments with $\mathrm{CuCl}_{2}$, the formation of the $\mathrm{Cu}(\mathrm{SG})_{2}$ intermediates seems also very likely in the presence of the CuFe catalyst. The widening on the spectra signals can be attributed to different equilibria established between $\mathrm{GSH}$ and $\mathrm{Cu}(\mathrm{SG})_{2}{ }^{42,53}$. The presence of very small amounts of paramagnetic $\left[\mathrm{Fe}-(\mathrm{SG})_{\mathrm{x}}\right.$ ] complexes cannot be discarded, and could also contribute to the widened signal. MS-ESI analysis of the solution at different reaction times (3-24h) yielded a mixture of Cu-SGderived fragments (Fig. S5) supporting the hypothesis of Cu-SG as reaction intermediate in the catalytic cycle. 


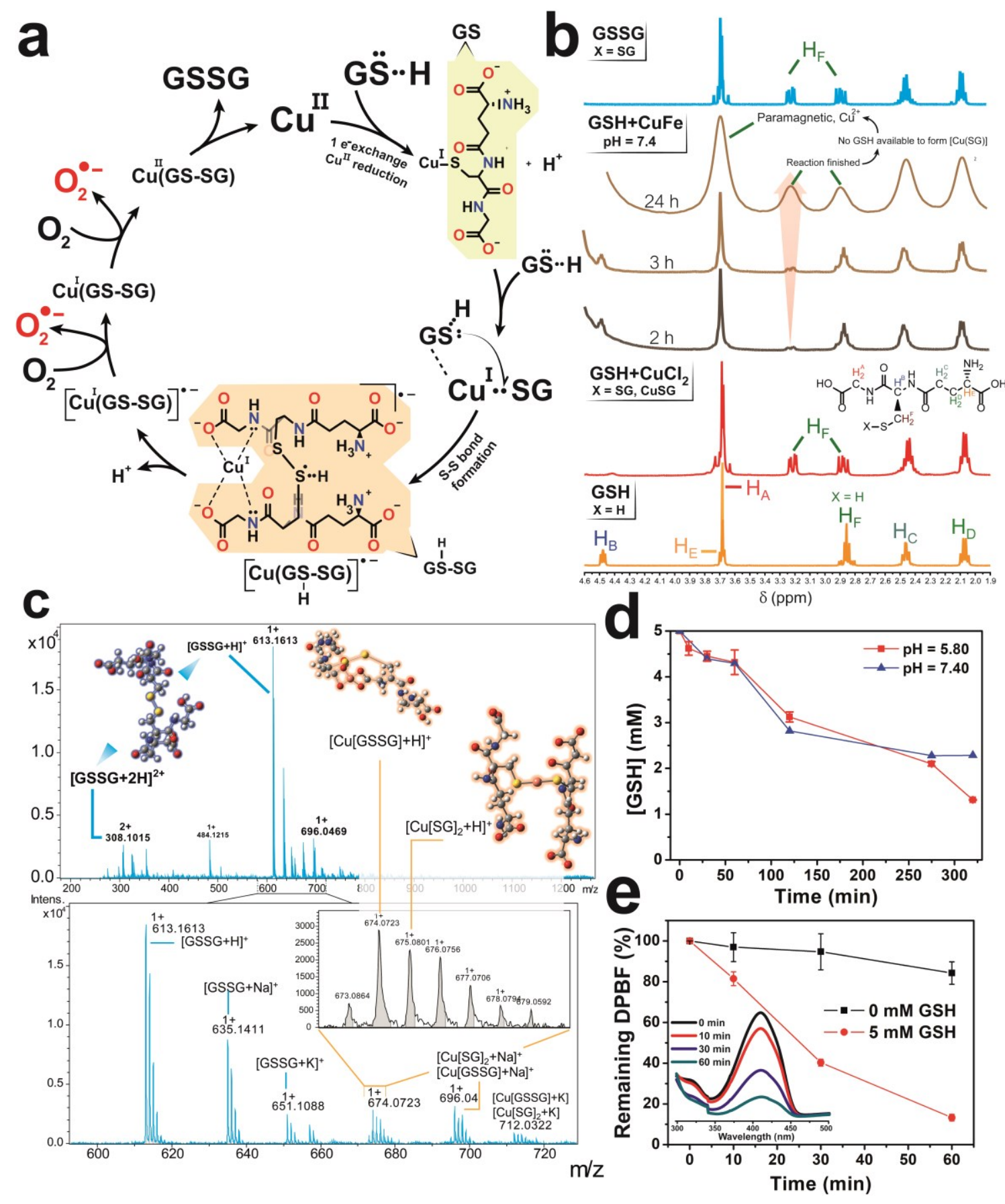

Fig. 3. Homogeneous catalysis of ionic $\mathrm{Cu}$ and $\mathbf{G S H}$ with $\mathrm{O}_{2}$. (a) Proposed homogeneous catalytic cycle for the Cu-assisted GSH oxidation. The reoxidation of $\mathrm{Cu}(\mathrm{SG})_{2}$ to $\mathrm{Cu}(\mathrm{GSSG})$ involves a reaction between the $\mathrm{Cu}(\mathrm{GS}-\mathrm{SG}) \cdot-$ complex and $\mathrm{O}_{2}$, yielding superoxide radical species $\left(\cdot \mathrm{O}_{2}{ }^{-}\right)$as reaction byproduct. The shaded areas correspond to the structure of GS and GS(H)SG, which are abbreviated for a better understanding; (b) ${ }^{1} \mathrm{H}$ NMR spectra of GSH, GSSG, GSH+CuCl 2 and $\mathrm{GSH}+\mathrm{CuFe}$ at different reaction times $\left(2,3\right.$ and $24 \mathrm{~h}$ ) with the corresponding proton assignments. ${ }^{1} \mathrm{H}$ NRM signal at $3.22 \mathrm{ppm}$ implies a chemical modification near -SH group of the native GSH molecule, either $\left[\mathrm{Cu}(\mathrm{SG})_{2}\right]^{+}$or $\mathrm{GSSG}$ formation. ${ }^{1} \mathrm{H}$ NMR reaction spectra at $24 \mathrm{~h}$ is clearly altered due to paramagnetism induced by free $\mathrm{Cu}^{2+}$ in solution, since the reaction is complete and no $\mathrm{GSH}$ is 
available to coordinate $\mathrm{Cu}^{2+}$; (c) HRMS-ESI from control experiments with $\mathrm{CuCl}_{2}+\mathrm{GSH}$ binary mixture in anaerobic conditions to quench the catalytic reaction. Two peaks at $\mathrm{m} / \mathrm{z}=613.16$ and 635.14 corresponding to [GSSG-H] ${ }^{+}$and $[\mathrm{GSSG}+\mathrm{Na}]^{+}$confirmed the generation of $\mathrm{GSH}$ oxidation product. The catalytic intermediate $\mathrm{Cu}(\mathrm{SG})_{2}$ is detected at $\mathrm{m} / \mathrm{z}=674$ and 675 , respectively; (d) Evolution of GSH concentration in the presence of the CuFe nanocatalyst at $\mathrm{pH} 7.40$ or 5.80 (adjusted with $\mathrm{HCO}_{3}{ }^{-}$ ), $37^{\circ} \mathrm{C},[\mathrm{GSH}]_{\circ}=5 \mathrm{mM}$; $[\mathrm{CuFe}]=0.1 \mathrm{mg} \cdot \mathrm{mL}^{-1}$; (e) Influence of $\mathrm{GSH}$ on the generation of anion superoxide species $\cdot \mathrm{O}_{2}{ }^{-}$as side-product of the $\mathrm{Cu}$-catalyzed $\mathrm{GSH}$ oxidation. The absorbance of DPBF at a wavelength of $411 \mathrm{~nm}$ is used as indirect probe; Reaction conditions: $\mathrm{pH}=7.40$ (adjusted with $\left.\mathrm{HCO}_{3}{ }^{-}\right),[\mathrm{GSH}]_{\mathrm{o}}=5 \mathrm{mM},[\mathrm{DPBF}]_{\mathrm{o}}=0.1 \mathrm{mM},[\mathrm{CuFe}]=0.1 \mathrm{mg} \cdot \mathrm{mL}^{-1}$.

GSH levels were monitored via Ultra Performance Liquid Chromatography-Photo Diode Array (UPLC-PDA) and revealed an important decrease at $\mathrm{pH}=7.40$ and 5.80 due to the catalytic activity of the $\mathrm{Cu}$ lixiviated by GSH (Fig. 4d). Remarkably, the presence of superoxide anion $\bullet^{-} \mathrm{O}_{2}^{-}$was also detected in the presence of GSH (Fig. 3e) using 1,3-Diphenylisobenzofuran (DPBF) as analytical probe (see Fig. S6). This allows us to propose a homogeneous catalytic reaction taking place mainly between the $\mathrm{Cu}^{2+}$ cations released from the CuFe catalyst and GSH (reaction step displayed in Fig. 3a): (i) $\mathrm{GSH}$ is able to bind and reduce aqueous $\mathrm{Cu}^{2+}$ species into $\mathrm{Cu}^{+}$through $-\mathrm{SH}$ group to form the $\mathrm{Cu}^{\prime}(\mathrm{SG})$ intermediate; (ii) A second GSH molecule is able to cleave the Cu-S bond to promote S-S formation through a radical process ${ }^{35}$. This step is thermodynamically favored since S-S bond energy is larger in comparison to Cu-S (429 vs $285 \mathrm{~kJ} / \mathrm{mol}$, respectively ${ }^{54}$ ). Following reported thiol oxidation kinetics $^{35}$, we propose the (iii) formation of the radical intermediate [Cu'(GSSG)] $\bullet-\mathrm{O}_{2}$ acting as electron acceptor withdraws an electron from this disulfide radical anion (Fig. S7) (iv) to yield the superoxide anion $\cdot \mathrm{O}_{2}{ }^{-}$that we have been able to detect together with $\mathrm{Cu}^{\prime}(\mathrm{GSSG})$. After this fast electron transfer, $(\mathbf{v})$ the $\mathrm{Cu}^{\prime}$ center rapidly oxidizes into $\mathrm{Cu}^{\prime \prime}$ in the presence of $\mathrm{O}_{2}{ }^{42}$. (vi) The catalytic cycle is restored after GSSG is detached from the coordination sphere of $\mathrm{Cu}^{\prime \prime}$ and replaced by a fresh GSH molecule. In the presence of a GSH excess, the Cu"(GSSG) complex exchanges GSSG by GSH to restart the catalytic cycle ${ }^{42}$. This process is also thermodynamically favored, since the formation constant (log $\mathrm{K}^{\prime}$ ) of $\mathrm{Cu}(\mathrm{SG})_{2}$ is significantly higher $(26.6)^{55}$ than $\mathrm{Cu}(\mathrm{GSSG})(3.63)^{56}$. The appearance of the $\mathrm{Cu}(\mathrm{SG})_{2}$ complex is also favored by $\mathrm{pH}$ values typically met in a tumor microenvironment (Fig S8-S9). Although the lixiviation of $\mathrm{Cu}$ triggered by GSH proceeds at a slower pace at $\mathrm{pH}=5.80$ (see Fig. $\mathbf{2 b}$ ), the percentage of $\mathrm{Cu}$ leached after $2 \mathrm{~h}$ of reaction reached $\sim 25 \%$, enough to produce the oxidation of roughly half of the initial GSH at that time (Fig. 3d).

The experiments with the CuFe NPs and GSH were also performed under acidic conditions. After 3 hours of reaction, ${ }^{1} \mathrm{H}-\mathrm{NMR}$ analysis (Fig. S3a) showed no meaningful fractions of GSSG/Fe(SG) complex formed. UPLC-PDA and MS-ESI analyses further corroborated the lower conversion of GSH in the presence of lixiviated Fe ions (Fig. S10 and Fig. S11, respectively). While an increase of the $[\mathrm{Fe}(\mathrm{SG})+\mathrm{H}]^{+}$signal was found after $24 \mathrm{~h}$ of reaction (Fig. S8a), a significant concentration of GSH 
was still present (Fig. S8b). These GSH-oxidation results together with previous MP-AES results at neutral pH (Fig. 2a) further suggest a limited influence of Fe in the homogeneous conversion of GSH. Two factors are key to justify these phenomena: (i) the much larger standard reduction potential of $\mathrm{Fe}^{3+/ 2+}\left(\mathrm{E}^{0}=+0.77 \mathrm{~V}\right.$ compared to $+0.153 \mathrm{~V}$ for $\left.\mathrm{Cu}^{2+++}\right)$ implies a comparatively slower catalytic cycle since the regeneration of $\mathrm{Fe}^{3+}$ species to restart the cycle requires a higher energy demand, an energy penalty analogous to that observed in Fenton-like processes ${ }^{57}$. (ii) The scarcity of labile $\mathrm{Fe}^{3+}$ available, both due to its slower leaching rate compared to $\mathrm{Cu}$ (Fig. 2a) and to the fact that at physiological $\mathrm{pH}$ released iron tend to rapidly form $\mathrm{Fe}(\mathrm{OH})_{3}$ species $^{58}$.

Heterogeneous catalase-mimicking response of the Fe-enriched solid nanoparticles. Given the strong $\mathrm{Cu}$ release in comparison with the much less intense Fe lixiviation, we investigated the morphological and catalytic properties of the progressively Fe-enriched nanoparticles. After the interaction with $\mathrm{GSH}$, most of $\mathrm{Cu}$ present in the nanoparticle is lixiviated to the aqueous media (see Fig. 2a). This was confirmed by High-Angle Annular Dark Field-Scanning Transmission Electron Microscopy (HAADF-STEM) and Energy Dispersive X-ray spectroscopy (EDX) mapping analysis of the nanoparticle before (Fig. 4a) and after (Fig. 4-b) reaction, revealing a very significant Fe enrichment following the preferential leaching of $\mathrm{Cu}$ after its interaction with $\mathrm{GSH}$. X-ray Photoelectron Spectroscopy (XPS) analysis of the CuFe nanocatalyst further confirms the strong reduction of the atomic percentage of copper at the surface in comparison with the original sample $(0.28$ atomic $\% \mathrm{Cu}$ after exposure, compared to 7.80 before, a 28-fold decrease, see Table S1-2). This is further supported by the significant reduction of the $\mathrm{Cu} 2 \mathrm{p}_{3 / 2}$ photoemission contribution after incubation with GSH (Fig. 4c). In addition, the oxidation state of $\mathrm{Cu}$ is strongly affected by the process. The reduced $\mathrm{Cu}$ content is now enriched in $\mathrm{Cu}^{+}$as shown by the ratios of the contributions at 932.6 and $934.3 \mathrm{eV}$ due to the reduction capability of $\mathrm{GSH}^{59}$, compared to the original sample with a higher ratio of $\mathrm{Cu}(\mathrm{II})$ to $\mathrm{Cu}(\mathrm{I})$ states $^{60}$ In contrast, the Fe surface atomic percentage slightly increases (see Table S1-2) as $\mathrm{Cu}$ species on the surface are removed. TEM analysis of the CuFe nanocatalyst after one hour of incubation with different GSH concentrations reveals that a certain reduction of nanoparticle size takes place in the presence of high $\mathrm{GSH}$ concentrations (i.e. $5 \mathrm{mM}$ ) as a consequence of metal leaching (Fig. 4d). XRD analysis showed an important decrease of the intensity corresponding to the (400) diffraction peak ${ }^{61}$ which accounts for the crystalline plane that includes four tetrahedral Cu sites (Fig. S12a-b).This reduction is also consistent with the selective loss of copper sites upon the incubation with GSH (Fig. S13a). In contrast, the Fe-enriched remaining solid nanoparticle matches well with the $\mathrm{XRD}$ patterns of $\mathrm{Fe}_{3} \mathrm{O}_{4}$ and $\mathrm{CuFe}_{2} \mathrm{O}_{4}$ (Fig. S12a).

Fe-based oxides have been reported as active catalysts to transform ROS species, such as $\cdot \mathrm{O}_{2}{ }^{-62,63}$ or $\mathrm{H}_{2} \mathrm{O}_{2}{ }^{7,27,64}$ into $\mathrm{H}_{2} \mathrm{O}_{2}$ and $\mathrm{O}_{2}$, respectively. Specifically, both species $\left(\cdot \mathrm{O}_{2}{ }^{-}\right.$and $\left.\mathrm{H}_{2} \mathrm{O}_{2}\right)$ are interesting in our system. $\cdot \mathrm{O}_{2}$ is a reaction side-product resulting from the homogeneous catalytic cycle (Fig. $\mathbf{3 b}$ ) and $\mathrm{H}_{2} \mathrm{O}_{2}$ is both an intratumoral overexpressed molecule ${ }^{29,65}$ and a reported by-product of $\mathrm{Cu}$ - 
catalyzed GSH oxidation in the homogeneous phase ${ }^{37}$. Thus, the Fe-enriched fraction of our catalyst is not a mere spectator of the homogeneous catalytic cycle. On the contrary, it becomes an active agent in generating oxygen from $\mathrm{H}_{2} \mathrm{O}_{2}$ under the hypoxic conditions (i.e. low $\mathrm{O}_{2}$ concentration) prevailing in TME (Fig. 4-e). This is clearly shown in where after each $\mathrm{H}_{2} \mathrm{O}_{2}$ injection a clear increase in the concentration of dissolved oxygen can be observed in the presence of the Fe-enriched catalyst (Fig. 4f), acting as a catalase-mimicking surrogate. This is in contrast with the results obtained when the same experiment was repeated in the presence of the $\mathrm{Cu}$ leachate from the catalyst, where no oxygen generation could be observed. The generated oxygen allows to complete and sustain the homogeneous $\mathrm{GSH}$-oxidation cycle, which needs $\mathrm{O}_{2}$ as final electron aceptor ${ }^{66}$. Interestingly, while the Fe-enriched solid nanocatalyst was able to decompose $\mathrm{H}_{2} \mathrm{O}_{2}$ into $\mathrm{O}_{2}$ (Fig. 4f), it showed negligible activity towards $\bullet \mathrm{OH}$ production through Fenton-like reaction (Fig. S13). 

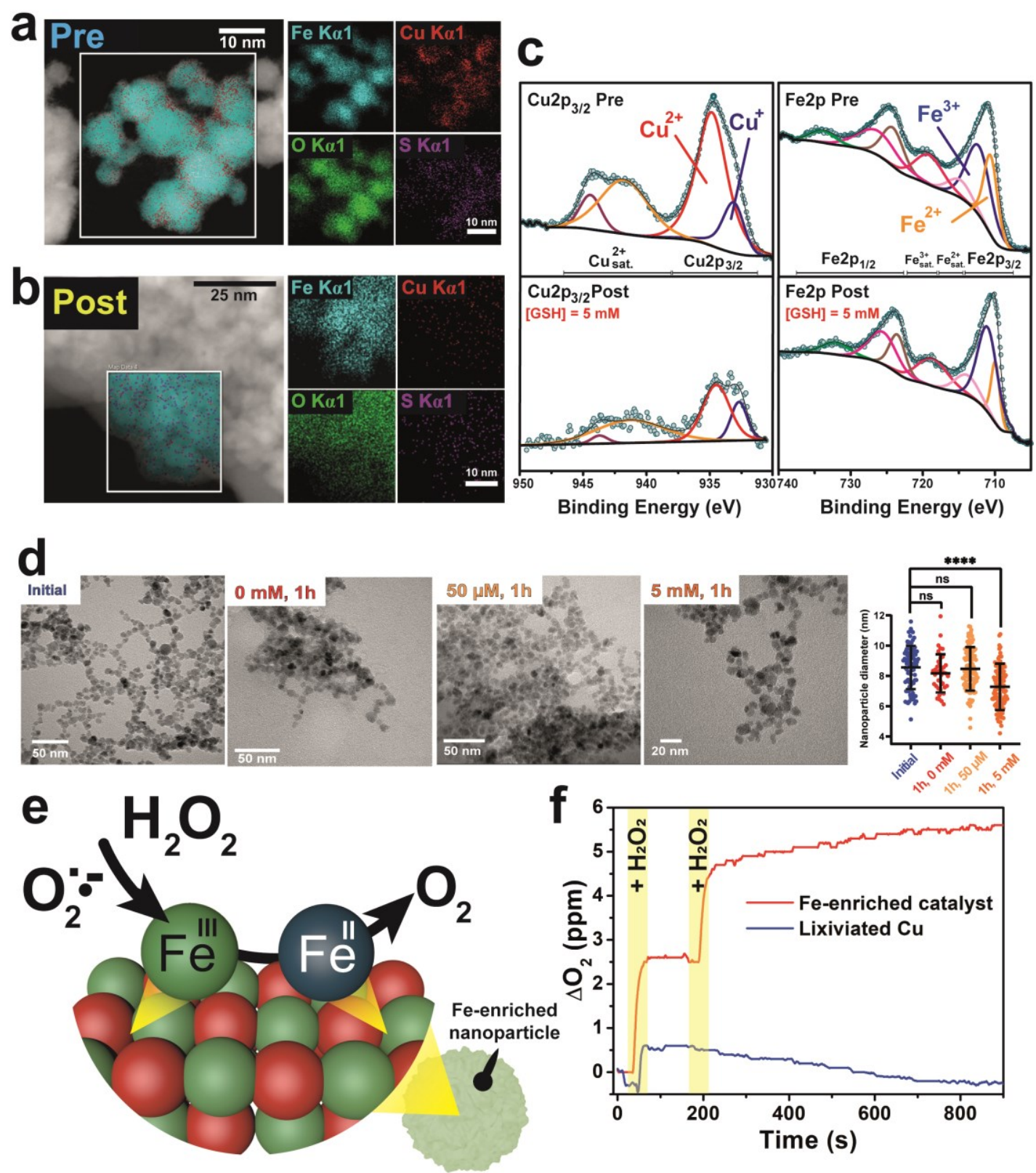

Fig. 4. Heterogeneous catalysis on the Fe-enriched nanoparticle surface: (a-b) STEM-EDX images before/after catalyst interaction with GSH. Prior to the GSH-triggered lixiviation of $\mathrm{Cu}, \mathrm{Fe}$ and $\mathrm{Cu}$ co-localize within the crystalline network of the nanoparticle oxide. However, after GSH exposition, $\mathrm{Cu}$ starts to be released and its presence in the nanoparticle is strongly reduced; (c) X-ray photoemission spectra corresponding to the $\mathrm{Cu}_{2} \mathrm{p}_{3 / 2}$ and $\mathrm{Fe} 2 \mathrm{p}$ regions before and after reaction of the CuFe nanocatalyst with GSH; As a consequence of leaching process, the intensity of $\mathrm{Cu}$ signal is close to noise; (d) TEM images of the CuFe nanocatalyst after 1 hour incubation with different GSH concentrations of relevant at the intracellular and extracellular levels. Size analysis of individual nanoparticles reveals a certain reduction of size in the presence of large concentrations (5 mM) of $\mathrm{GSH}$; (f) Catalytic $\mathrm{O}_{2}$ generation from reduced oxygen species resultant from GSH oxidation (mainly - $\mathrm{O}_{2}{ }^{-}$and $\mathrm{H}_{2} \mathrm{O}_{2}$ ) assisted by the resultant Fe-enriched nanoparticle after $\mathrm{Cu}$ leaching $(\mathbf{g}) \mathrm{O}_{2}$ generation 
capabilities of the Fe-enriched nanoparticles and of the supernatant containing leached $\mathrm{Cu}$ cations at $\mathrm{pH}=7.40 ;\left[\mathrm{H}_{2} \mathrm{O}_{2}\right]_{0}=1 \mathrm{mM},[\mathrm{CuFe}]=0.1 \mathrm{mg} \cdot \mathrm{mL}^{-1}$; Addition of $\mathrm{H}_{2} \mathrm{O}_{2}$ is highlighted.

\section{Interplay of homogeneous and heterogeneous catalysis in healthy and cancer cells with} different GSH levels. To evaluate the biological action of the CuFe nanocatalyst additional experiments were carried out against different cell lines. Several tumor cell lines were specifically selected for their intrinsic high GSH levels, while healthy cell lines (i.e. fibroblasts and mesenchymal cells) with lower GSH concentrations were used as control ${ }^{67,68}$. Specifically, four different tumor cell lines were chosen in order to assess the cytotoxic effect of this nanocatalyst: U251-MG and U87-MG (both malignant glioblastoma cell lines), SKOV-3 (ovarian cancer cell line) and HeLa (cervical cancer cell line). The aim of the study was to compare the behavior of cell lines against the action of our nanocatalyst, since it is expected to have a variable effect depending on the specific GSH content.

The results of the cytotoxicity studies after different times of incubation with the CuFe nanocatalyst (Fig. 5a) revealed a clear effect: the viability of the four tumor cell lines was reduced, even at low concentrations of the catalyst and reduced incubation times (see Fig. 5a). In contrast, the non-tumoral cell lines remained viable in the presence of much higher concentrations of the catalyst. The microscopy study is consistent with the cytotoxicity results, showing a marked impairment of morphology for the tumoral cell lines exposed to the CuFe catalyst (Fig. 5b).

Up to now, the interaction between $\mathrm{Cu}$ and Fe based nanoparticles and $\mathrm{GSH}$ has been either interpreted from the perspective of a heterogeneous process taking place at the nanoparticle-liquid interface or directly neglected. We have detected $\cdot \mathrm{O}_{2}{ }^{-}$as the reaction by-product of Cu-catalyzed GSH oxidation (although $\mathrm{H}_{2} \mathrm{O}_{2}$ is also reported ${ }^{37}$ ), a reaction taking place homogeneously with leached $\mathrm{Cu}$ species, i.e. while GSH interacts with the surface to produce the release of $\mathrm{Cu}(\mathrm{I})$ species, the $\mathrm{GSH}$ oxidation itself would be a homogeneous process taking place in the bulk of the solution and not on the catalyst particle. However, both reaction byproducts $\cdot \mathrm{O}_{2}{ }^{-}$and $\mathrm{H}_{2} \mathrm{O}_{2}$ are capable of interacting with the remaining Fe-enriched nanoparticle which acts as an heterogeneous catalyst yielding $\mathrm{O}_{2}$, which in turn is necessary to sustain the homogeneous GSH oxidation.

Taking into account the above results, we propose the following reaction mechanism (see Fig. 6): (i) In a first step, nucleophilic thiol (-SH) groups from $\mathrm{GSH}$ promote the release of $\mathrm{Cu}$ species from the nanocatalyst crystalline network. GSH overexpressed in TME forms a coordination complex with released $\mathrm{Cu},\left(\mathrm{Cu}(\mathrm{SG})_{2}\right)$. The formation of this complex effectively removes free $\mathrm{Cu}(\mathrm{I})$ species from the environment, shifting liquid phase equilibria and increasing the rate of $\mathrm{Cu}$ leaching; (ii) The $\mathrm{Cu}(\mathrm{SG})_{2}$ complex starts a homogeneous catalytic cycle where GSH is finally oxidized to GSSG by dissolved $\mathrm{O}_{2}$; This latter process entails an electron transfer from [Cu'(GSSG)]•- to $\mathrm{O}_{2}$, promoting the generation of $\cdot \mathrm{O}_{2}{ }^{-}$radicals which readily (iii) react with the $\mathrm{Fe}{ }^{\text {III }}$ sites remaining in the solid nanocatalyst through a 
Haber-Weiss reaction ${ }^{69,70}$ to regenerate $\mathrm{O}_{2}$ that feeds the homogeneously Cu-catalyzed reaction. Moreover, additional $\mathrm{O}_{2}$ is produced by the Fe-enriched catalytic nanoparticle using environmental $\mathrm{H}_{2} \mathrm{O}_{2}$ (Figure 4f). Finally, (iv) GSSG is released from the coordination sphere of $\mathrm{Cu}^{2+}$, which becomes available to be reduced by $\mathrm{GSH}$ and re-start the catalytic cycle. The proposed mechanism constitutes a perfect example of how two catalytic processes, namely the homogeneous Cu-catalyzed GSH oxidation and the heterogeneously catalyzed processes of $\mathrm{H}_{2} \mathrm{O}_{2}$ decomposition and $\bullet \mathrm{O}_{2}$ reaction are synergistically coupled to provide the efficient oxidation of a key tumor metabolite (GSH) allowing to circumvent $\mathrm{O}_{2}$-scarcity in tumor microenvironment. 

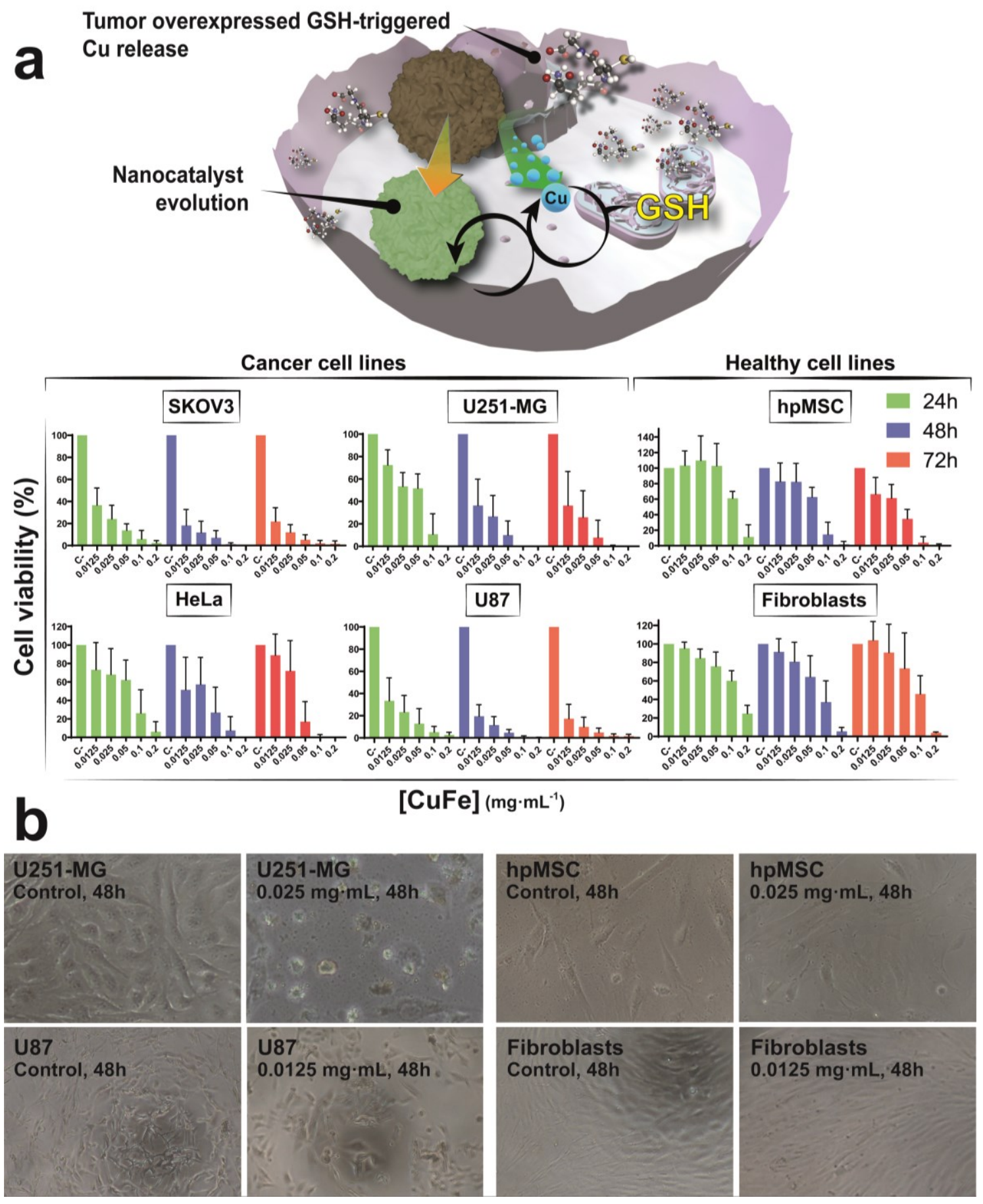

Fig. 5. Cancer cell lines with overexpressed GSH levels are affected by CuFe-triggered catalysis. (a) Cell viability study of CuFe nanocatalyst with different cancer (SKOV-3, U251-MG, HeLa and U87) and non-tumoral (hpMSC and fibroblasts) cell lines. The higher concentration of GSH in cancer cell lines enhances the action of the CuFe nanocatalyst, decreasing GSH levels while simultaneously generating superoxide species; (b) Optical microscopy images of tumoral (U251-MG, U87) and healthy (hpMSC, fibroblasts) cell lines at different CuFe concentrations. 
In situ complex formation

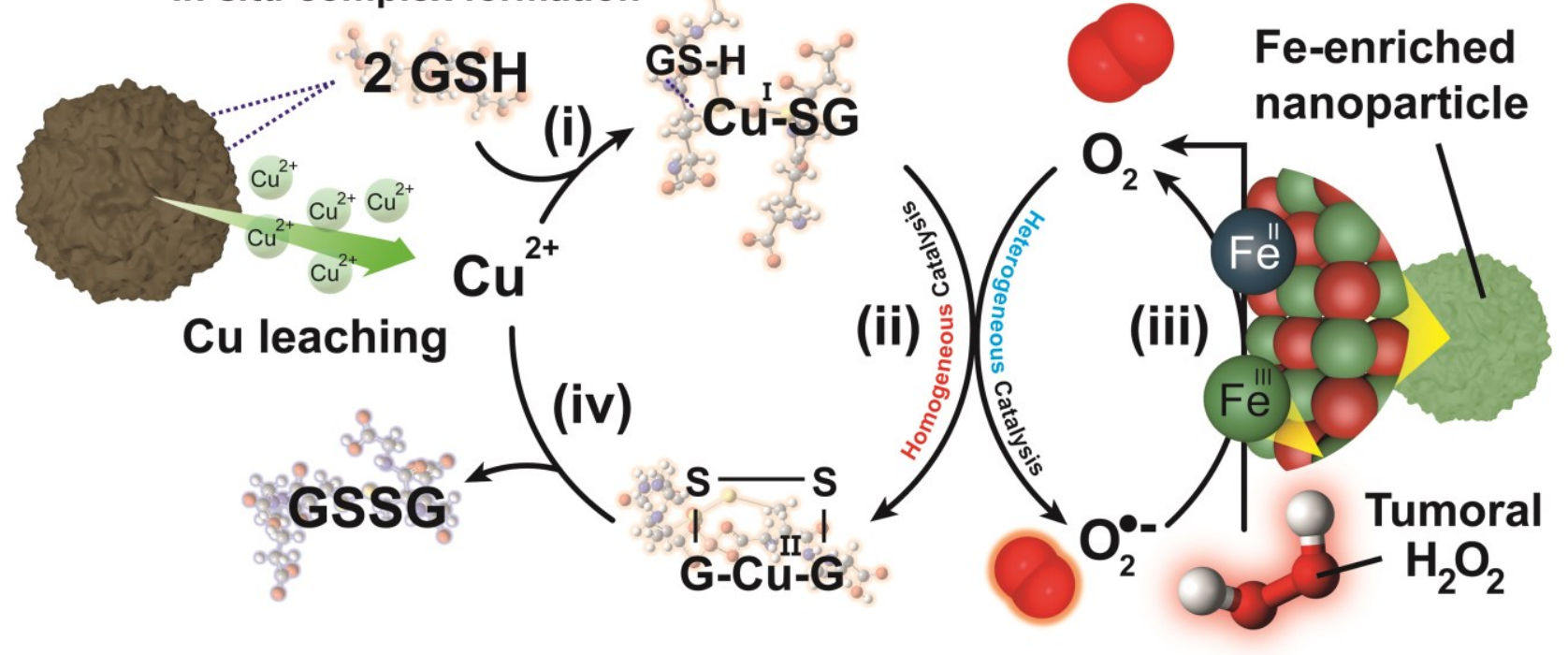

Fig. 6. Complete homogeneous-heterogeneous interplay for the CuFe nanoparticles in the presence of $\mathrm{GSH}$ and $\mathrm{O}_{2}$ : (i) In a first step, GSH triggers Cu-release from the spinel nanostructure (ii) excess $\mathrm{GSH}$ is able to form an organometallic complex with $\mathrm{Cu}$ through thiol (-SH) groups to stabilize $\mathrm{Cu}^{\prime}$ (iii) Molecular $\mathrm{O}_{2}$ accepts electrons from $\mathrm{Cu}(\mathrm{SG})_{2}$ complex to yield superoxide $\cdot \mathrm{O}_{2}{ }^{-}$and $\mathrm{Cu}$ (GSSG). (iv) In a heterogeneously coupled process, as-generated $\cdot \mathrm{O}_{2}$ - donates electrons to the remaining Fe-enriched surface of the solid heterogeneous nanocatalyst in a process that generates oxygen needed for step iii. A parallel enzyme-mimicking process of $\mathrm{H}_{2} \mathrm{O}_{2}$ decomposition also takes place on the Fe-enriched catalyst, contributing additional oxygen generation.

\section{CONCLUSIONS}

Processes promoted by heterogeneous catalysts are not necessarily of a purely heterogeneous nature. Here we demonstrate that a combination of homogeneous and heterogeneous processes can originate from a copper-iron based nanocatalyst under conditions that are relevant in the tumor microenvironment. The main part of the contributing reactions take place in a homogeneous cycle catalyzed by released $\mathrm{Cu}$ species. The results shed light on the complexity of the processes taking place in developing fields such as Nanocatalytic Cancer Therapy. As demonstrated in this work for a CuFe hybrid nanocatalyst, lixiviation mechanisms induced by specific biomolecules with a strong presence in the TME such as GSH may lead to new catalytic scenarios where homogeneous and heterogeneous processes become interrelated events. This means that catalyst design becomes more complex, since it has to take into account the effect of environmental species on the stability of the catalyst, but also more powerful, since leaching processes can be engineered to yield synergistic 
catalytic actions. Under this scenario, the design of the catalyst will consider not only its ability to favour specific surface reactions, but also its role as a reservoir for the long-term release of active ions in response to the stimuli of the chemical environment. This point of view will be key to develop novel nanoparticles capable of acting as successful bio-orthogonal catalysts.

\section{Acknowledgements}

Financial support from the European Research Council (ERC Advanced Grant CADENCE number 742684 ) is gratefully acknowledged. The TEM measurements were conducted at the Laboratorio de Microscopias Avanzadas, Instituto de Nanociencia y Materiales de Aragon, Universidad de Zaragoza, Spain. The synthesis of materials has been performed by the Platform of Production of Biomaterials and Nanoparticles of the NANBIOSIS ICTS, more specifically by the Nanoparticle Synthesis Unit of the CIBER in BioEngineering, Biomaterials \& Nanomedicine (CIBER-BBN). J.B-A. acknowledges the Spanish Government for an FPU predoctoral contract. M. E. acknowledges the Diputacion General de Aragon (DGA) for a predoctoral contract. The authors thank Dr. Javier Calzada and Dr. Silvia Irusta for their help with UPLC and XPS measurements.

\section{Author Contributions}

J.B.-A. and J.L.H. prepared and characterized the materials. J.B-A., M.E. and E. U. performed the experiments and analysed the data; E.U, P.M-D., J.L.H. and J.S. designed, coordinated and supervised the research and analysed the data. J.B-A, J.L.H. and J.S. wrote the paper with contribution and approval of all the authors.

\section{REFERENCES}

1 Ding, Y., Dai, Y., Wu, M. \& Li, L. Glutathione-Mediated Nanomedicines for Cancer Diagnosis and Therapy. Chemical Engineering Journal, 128880, doi:https://doi.org/10.1016/i.cej.2021.128880 (2021).

2 Acharya, A., Das, I., Chandhok, D. \& Saha, T. Redox regulation in cancer: a double-edged sword with therapeutic potential. Oxid Med Cell Longev 3, 23-34, doi:10.4161/oxim.3.1.10095 (2010).

3 Nelson, D. L., Lehninger, A. L. \& Cox, M. M. Lehninger Principles of Biochemistry. (W. H. Freeman, 2008).

4 Balendiran, G. K., Dabur, R. \& Fraser, D. The role of glutathione in cancer. Cell Biochemistry and Function 22, 343-352, doi:https://doi.org/10.1002/cbf.1149 (2004). 
5 Traverso, $\mathrm{N}$. et al. Role of glutathione in cancer progression and chemoresistance. Oxid Med Cell Longev 2013, 972913-972913, doi:10.1155/2013/972913 (2013).

6 Wang, L., Huo, M., Chen, Y. \& Shi, J. Tumor Microenvironment-Enabled Nanotherapy. Advanced healthcare materials 7, e1701156, doi:10.1002/adhm.201701156 (2018).

7 Li, S. et al. A Nanozyme with Photo-Enhanced Dual Enzyme-Like Activities for Deep Pancreatic Cancer Therapy. Angewandte Chemie International Edition 58, 12624-12631, doi:https://doi.org/10.1002/anie.201904751 (2019).

8 Sun, Q. et al. Recent advances on endogenous/exogenous stimuli-triggered nanoplatforms for enhanced chemodynamic therapy. Coordination Chemistry Reviews 451, 214267, doi:https://doi.org/10.1016/j.ccr.2021.214267 (2022).

9 Zhang, X., Lin, Y. \& Gillies, R. J. Tumor pH and Its Measurement. Journal of Nuclear Medicine 51, 1167, doi:10.2967/jnumed.109.068981 (2010).

$10 \mathrm{Yu}, \mathrm{L}$. et al. "Manganese Extraction" Strategy Enables Tumor-Sensitive Biodegradability and Theranostics of Nanoparticles. Journal of the American Chemical Society 138, 9881-9894, doi:10.1021/jacs.6b04299 (2016).

11 Yue, L. et al. pH-Responsive, Self-Sacrificial Nanotheranostic Agent for Potential In Vivo and In Vitro Dual Modal MRI/CT Imaging, Real-Time, and In Situ Monitoring of Cancer Therapy. Bioconjugate chemistry 28, 400-409, doi:10.1021/acs.bioconjchem.6b00562 (2017).

12 Jing, X. et al. Intelligent nanoflowers: a full tumor microenvironment-responsive multimodal cancer theranostic nanoplatform. Nanoscale 11, 15508-15518, doi:10.1039/C9NR04768A (2019).

13 Wang, S. et al. Arginine-Rich Manganese Silicate Nanobubbles as a Ferroptosis-Inducing Agent for Tumor-Targeted Theranostics. ACS Nano 12, 12380-12392, doi:10.1021/acsnano.8b06399 (2018).

$14 \mathrm{Xu}$, J. et al. Tumor Microenvironment-Responsive Mesoporous MnO2-Coated Upconversion Nanoplatform for Self-Enhanced Tumor Theranostics. Advanced Functional Materials 28, 1803804, doi:10.1002/adfm.201803804 (2018).

15 Jiang, F. et al. Biocompatible CuO-decorated carbon nanoplatforms for multiplexed imaging and enhanced antitumor efficacy via combined photothermal therapy/chemodynamic therapy/chemotherapy. Science China Materials 63, 1818-1830, doi:10.1007/s40843-019-1397-0 (2020).

16 Guo, G. et al. Space-Selective Chemodynamic Therapy of CuFe5O8 Nanocubes for Implant-Related Infections. ACS Nano 14, 13391-13405, doi:10.1021/acsnano.0c05255 (2020). 
$17 \mathrm{Xu}$, J. et al. All-in-One Theranostic Nanomedicine with Ultrabright Second NearInfrared Emission for Tumor-Modulated Bioimaging and Chemodynamic/Photodynamic Therapy. ACS Nano 14, 9613-9625, doi:10.1021/acsnano.0c00082 (2020).

18 Wu, H. et al. Smart Porous Core-Shell Cuprous Oxide Nanocatalyst with High Biocompatibility for Acid-Triggered Chemo/Chemodynamic Synergistic Therapy. Small 16, 2001805, doi:https://doi.org/10.1002/smll.202001805 (2020).

$19 \mathrm{Li}, \mathrm{Y}$. et al. Decoration of Cisplatin on 2D Metal-Organic Frameworks for Enhanced Anticancer Effects through Highly Increased Reactive Oxygen Species Generation. ACS Applied Materials \& Interfaces 10, 30930-30935, doi:10.1021/acsami.8b12800 (2018).

20 Yang, C. et al. Programmable NIR-II Photothermal-Enhanced StarvationPrimed Chemodynamic Therapy using Glucose Oxidase-Functionalized Ancient Pigment Nanosheets. Small 16, 2001518, doi:https://doi.org/10.1002/smll.202001518 (2020).

21 Gunawan, C., Teoh, W. Y., Marquis, C. P. \& Amal, R. Cytotoxic Origin of Copper(II) Oxide Nanoparticles: Comparative Studies with Micron-Sized Particles, Leachate, and Metal Salts. ACS Nano 5, 7214-7225, doi:10.1021/nn2020248 (2011).

22 Wang, Z., von dem Bussche, A., Kabadi, P. K., Kane, A. B. \& Hurt, R. H. Biological and Environmental Transformations of Copper-Based Nanomaterials. ACS Nano 7, 8715-8727, doi:10.1021/nn403080y (2013).

23 Wang, Z. et al. CuO Nanoparticle Interaction with Human Epithelial Cells: Cellular Uptake, Location, Export, and Genotoxicity. Chemical Research in Toxicology 25, 1512-1521, doi:10.1021/tx3002093 (2012).

24 Eremin, D. B. \& Ananikov, V. P. Understanding active species in catalytic transformations: From molecular catalysis to nanoparticles, leaching, "Cocktails" of catalysts and dynamic systems. Coordination Chemistry Reviews 346, 2-19, doi:https://doi.org/10.1016/j.ccr.2016.12.021 (2017).

25 Chang, M. et al. A Multifunctional Cascade Bioreactor Based on HollowStructured Cu2MoS4 for Synergetic Cancer Chemo-Dynamic Therapy/Starvation Therapy/Phototherapy/Immunotherapy with Remarkably Enhanced Efficacy. Advanced Materials 31, 1905271, doi:https://doi.org/10.1002/adma.201905271 (2019).

26 Yin, S.-Y. et al. Persistent Regulation of Tumor Microenvironment via Circulating Catalysis of MnFe2O4@Metal-Organic Frameworks for Enhanced 
Photodynamic Therapy. Advanced Functional Materials 29, 1901417, doi:https://doi.org/10.1002/adfm.201901417 (2019).

27 Liu, Y. et al. All-in-One Theranostic Nanoagent with Enhanced Reactive Oxygen Species Generation and Modulating Tumor Microenvironment Ability for Effective Tumor Eradication. ACS Nano 12, 4886-4893, doi:10.1021/acsnano.8b01893 (2018).

28 Wang, Z. et al. Synthesis of one-for-all type Cu5FeS4 nanocrystals with improved near infrared photothermal and Fenton effects for simultaneous imaging and therapy of tumor. Journal of Colloid and Interface Science 592, 116-126, doi:https://doi.org/10.1016/j.jcis.2021.02.037 (2021).

29 Szatrowski, T. P. \& Nathan, C. F. Production of Large Amounts of Hydrogen Peroxide by Human Tumor Cells. Cancer Research 51, 794 (1991).

30 Wang, X., Zhong, X., Liu, Z. \& Cheng, L. Recent progress of chemodynamic therapy-induced combination cancer therapy. Nano Today 35, 100946, doi:https://doi.org/10.1016/j.nantod.2020.100946 (2020).

31 Ge, E. J. et al. Connecting copper and cancer: from transition metal signalling to metalloplasia. Nature Reviews Cancer, doi:10.1038/s41568-021-00417-2 (2021).

32 Hedberg, J., Blomberg, E. \& Odnevall Wallinder, I. In the Search for Nanospecific Effects of Dissolution of Metallic Nanoparticles at Freshwater-Like Conditions: A Critical Review. Environmental Science \& Technology 53, 40304044, doi:10.1021/acs.est.8b05012 (2019).

33 Tummanapelli, A. K. \& Vasudevan, S. Ab Initio MD Simulations of the Brønsted Acidity of Glutathione in Aqueous Solutions: Predicting pKa Shifts of the Cysteine Residue. The Journal of Physical Chemistry B 119, 15353-15358, doi:10.1021/acs.jpcb.5b10093 (2015).

34 Wall, S., Oh, J.-Y., Diers, A. \& Landar, A. Oxidative Modification of Proteins: An Emerging Mechanism of Cell Signaling. 3, doi:10.3389/fphys.2012.00369 (2012).

35 Nagy, P. Kinetics and mechanisms of thiol-disulfide exchange covering direct substitution and thiol oxidation-mediated pathways. Antioxidants \& redox signaling 18, 1623-1641, doi:10.1089/ars.2012.4973 (2013).

36 Rabenstein, D. L. Nuclear magnetic resonance studies of the acid-base chemistry of amino acids and peptides. I. Microscopic ionization constants of glutathione and methylmercury-complexed glutathione. Journal of the American Chemical Society 95, 2797-2803, doi:10.1021/ja00790a009 (1973). 
37 Ngamchuea, K., Batchelor-McAuley, C. \& Compton, R. G. The Copper(II)Catalyzed Oxidation of Glutathione. Chemistry - A European Journal 22, 15937-15944, doi:https://doi.org/10.1002/chem.201603366 (2016).

38 Speisky, H. et al. Cu(I)-Glutathione complex: A potential source of superoxide radicals generation. Bioorganic \& Medicinal Chemistry 16, 6568-6574, doi:https://doi.org/10.1016/i.bmc.2008.05.026 (2008).

39 Speisky, H. et al. Generation of superoxide radicals by copper-glutathione complexes: Redox-consequences associated with their interaction with reduced glutathione. Bioorganic \& Medicinal Chemistry 17, 1803-1810, doi:https://doi.org/10.1016/j.bmc.2009.01.069 (2009).

40 Speisky, H. et al. Cu(I)-glutathione complex: a potential source of superoxide radicals generation. Bioorganic \& medicinal chemistry 16, 6568-6574, doi:10.1016/j.bmc.2008.05.026 (2008).

41 Aliaga, M. E., Carrasco-Pozo, C., López-Alarcón, C. \& Speisky, H. The Cu(I)glutathione complex: factors affecting its formation and capacity to generate reactive oxygen species. Transition Metal Chemistry 35, 321-329, doi:10.1007/s11243-010-9330-9 (2010).

42 Aliaga, M. E., López-Alarcón, C., Bridi, R. \& Speisky, H. Redox-implications associated with the formation of complexes between copper ions and reduced or oxidized glutathione. Journal of Inorganic Biochemistry 154, 78-88, doi:https://doi.org/10.1016/j.jinorgbio.2015.08.005 (2016).

43 Morgan, M. T., Nguyen, L. A. H., Hancock, H. L. \& Fahrni, C. J. Glutathione limits aquacopper $(\mathrm{I})$ to sub-femtomolar concentrations through cooperative assembly of a tetranuclear cluster. Journal of Biological Chemistry 292, 2155821567, doi:10.1074/jbc.M117.817452 (2017).

44 Ciriolo, M. R., Desideri, A., Paci, M. \& Rotilio, G. Reconstitution of Cu,Znsuperoxide dismutase by the $\mathrm{Cu}(\mathrm{l})$.glutathione complex. The Journal of biological chemistry 265, 11030-11034 (1990).

45 Pearson, R. G. Hard and Soft Acids and Bases. Journal of the American Chemical Society 85, 3533-3539, doi:10.1021/ja00905a001 (1963).

46 Moggach, S. A. et al. Pressure induced phase transitions in the tripeptide glutathione to $5.24 \mathrm{GPa}$ : the crystal structure of glutathione-II at $2.94 \mathrm{GPa}$ and glutathione-III at 3.70 GPa. 12, 2587-2595 (2010).

47 Görbitz, C. J. A. C. S. A Redetermination of the Crystal and Molecular Structure of Glutathione (yL-Glutamyl-L-cysteinylglycine) at $120 \mathrm{~K} .41,362-366$ (1987).

48 Wright, W. J. A. C. The crystal structure of glutathione. 11, 632-642 (1958). 
49 Jelsch, C. \& Didierjean, C. J. A. C. S. C. C. S. C. The oxidized form of glutathione. 55, 1538-1540 (1999).

50 Kretzschmar, J., Brendler, E., Wagler, J. \& Schmidt, A.-C. J. J. o. h. m. Kinetics and activation parameters of the reaction of organoarsenic $(\mathrm{V})$ compounds with glutathione. 280, 734-740 (2014).

51 Gao, Z. et al. The facile and additive-free synthesis of a cell-friendly iron (III)glutathione complex. 49, 10574-10579 (2020).

52 Qi, W. et al. Glutathione Complexed Fe-S Centers. Journal of the American Chemical Society 134, 10745-10748, doi:10.1021/ja302186j (2012).

53 Corazza, A., Harvey, I. \& Sadler, P. J. 1H,13C-NMR and X-ray absorption studies of copper(I) glutathione complexes. European journal of biochemistry 236, 697-705, doi:10.1111/j.1432-1033.1996.0697d.x (1996).

54 Dean, J. A. \& Lange, N. A. Lange's Handbook of Chemistry. (McGraw-Hill, 1992).

55 Walsh, M. J. \& Ahner, B. A. Determination of stability constants of $\mathrm{Cu}(\mathrm{I}), \mathrm{Cd}(\mathrm{II})$ \& $\mathrm{Zn}(\mathrm{II})$ complexes with thiols using fluorescent probes. Journal of Inorganic Biochemistry 128, 112-123, doi:https://doi.org/10.1016/j.jinorgbio.2013.07.012 (2013).

56 Shtyrlin, V. G., Zyavkina, Y. I., Ilakin, V. S., Garipov, R. R. \& Zakharov, A. V. Structure, stability, and ligand exchange of copper(II) complexes with oxidized glutathione. Journal of Inorganic Biochemistry 99, 1335-1346, doi:https://doi.org/10.1016/j.jinorgbio.2005.03.008 (2005).

57 Shen, X., Wang, Z., Gao, X. \& Zhao, Y. Density Functional Theory-Based Method to Predict the Activities of Nanomaterials as Peroxidase Mimics. ACS Catalysis 10, 12657-12665, doi:10.1021/acscatal.0c03426 (2020).

58 Crichton, R., Crichton, R. R. \& Boelaert, J. R. Inorganic Biochemistry of Iron Metabolism: From Molecular Mechanisms to Clinical Consequences. (Wiley, 2001).

59 Ma, B. et al. Self-Assembled Copper-Amino Acid Nanoparticles for in Situ Glutathione "AND" $\mathrm{H} 2 \mathrm{O} 2$ Sequentially Triggered Chemodynamic Therapy. Journal of the American Chemical Society 141, 849-857, doi:10.1021/jacs.8b08714 (2019).

60 Biesinger, M. C. Advanced analysis of copper X-ray photoelectron spectra. Surface and Interface Analysis 49, 1325-1334, doi:https://doi.org/10.1002/sia.6239 (2017).

61 Liu, Y. et al. Multifunctional Magnetic Copper Ferrite Nanoparticles as Fentonlike Reaction and Near-Infrared Photothermal Agents for Synergetic 
Antibacterial Therapy. ACS Applied Materials \& Interfaces 11, 31649-31660, doi:10.1021/acsami.9b10096 (2019).

62 Wang, W., Jiang, X. \& Chen, K. Iron phosphate microflowers as peroxidase mimic and superoxide dismutase mimic for biocatalysis and biosensing. Chemical Communications 48, 7289-7291, doi:10.1039/C2CC32429F (2012).

63 Guo, S., Han, Y. \& Guo, L. Mechanistic Study of Catalase- and Superoxide Dismutation-Mimic Activities of Cobalt Oxide Nanozyme from First-Principles Microkinetic Modeling. Catalysis Surveys from Asia 24, 70-85, doi:10.1007/s10563-019-09290-4 (2020).

64 Zhang, Y. et al. Hollow magnetic nanosystem-boosting synergistic effect between magnetic hyperthermia and sonodynamic therapy via modulating reactive oxygen species and heat shock proteins. Chemical Engineering Journal 390, 124521, doi:https://doi.org/10.1016/j.cej.2020.124521 (2020).

65 Liu, C. et al. Biodegradable Biomimic Copper/Manganese Silicate Nanospheres for Chemodynamic/Photodynamic Synergistic Therapy with Simultaneous Glutathione Depletion and Hypoxia Relief. ACS Nano 13, 4267-4277, doi:10.1021/acsnano.8b09387 (2019).

66 Huo, M., Wang, L., Chen, Y. \& Shi, J. Tumor-selective catalytic nanomedicine by nanocatalyst delivery. Nature Communications 8, 357, doi:10.1038/s41467017-00424-8 (2017).

67 Zhao, Y. et al. Missing-Linker-Assisted Artesunate Delivery by Metal-Organic Frameworks for Synergistic Cancer Treatment. Angewandte Chemie International Edition n/a, doi:https://doi.org/10.1002/anie.202112128 (2021).

68 Kuppusamy, P. et al. Noninvasive Imaging of Tumor Redox Status and Its Modification by Tissue Glutathione Levels. Cancer Research 62, 307 (2002).

69 Weiss, J. \& Humphrey, C. W. Reaction between Hydrogen Peroxide and Iron Salts. Nature 163, 691-691, doi:10.1038/163691a0 (1949).

70 Hayyan, M., Hashim, M. A. \& AINashef, I. M. Superoxide Ion: Generation and Chemical Implications. Chemical Reviews 116, 3029-3085, doi:10.1021/acs.chemrev.5b00407 (2016). 


\section{Supplementary Information}

Leveraging the interplay between homogeneous and heterogeneous catalytic mechanisms: copper-iron nanoparticles working under chemically relevant tumor conditions

Javier Bonet-Aleta ${ }^{a, b, c}$, Miguel Encinas ${ }^{a, b, c}$, Esteban Urriolabeitia ${ }^{d}$, Pilar Martin-Duque ${ }^{b, e, f, g}$, Jose L. Hueso $^{\mathrm{a}, \mathrm{b}, \mathrm{c}}$, Jesus Santamaria ${ }^{\mathrm{a}, \mathrm{b}, \mathrm{c}, \mathrm{f}}$

anstitute of Nanoscience and Materials of Aragon (INMA), CSIC-Universidad de Zaragoza, Campus Río Ebro, Edificio I+D, C/ Poeta Mariano Esquillor, s/n, 50018, Zaragoza, Spain.

betworking Research Center in Biomaterials, Bioengineering and Nanomedicine (CIBER-BBN), Madrid, Spain. Instituto de Salud Carlos III; 28029, Madrid, Spain.

'Department of Chemical and Environmental Engineering; University of Zaragoza, Spain; Campus Rio Ebro, C/María de Luna, 3, 50018 Zaragoza, Spain.

'Instituto de Síntesis Química y Catálisis Homogénea, ISQCH (CSIC-Universidad de Zaragoza), 50009 Zaragoza, Spain.

eInstituto Aragonés de Ciencias de la Salud (IACS), Avenida San Juan Bosco, 13, 50009 Zaragoza, Spain.

fInstituto de Investigación Sanitaria (IIS) Aragón, Avenida San Juan Bosco, 13, 50009 Zaragoza, Spain.

9Fundación Araid. Av. de Ranillas 1-D, 50018 Zaragoza, Spain.

\section{TABLE OF SUPPLEMENTARY CONTENTS}

S1. Chemicals and Materials. 28

S2. Characterization techniques. 28

S3. Synthesis of CuFe-DMSA nanoparticles. 28

S4. Metal leaching study by Microwave Plasma-Atomic Emission Spectroscopy. 29

S5. ${ }^{1}$ HNMR-study of CuFe-GSH interaction. 29

S6. Mass spectroscopy analysis of the reaction. 30

S7. Catalytic GSH depletion. 30

S8. UPLC-PDA equipment for GSH quantification. 30 
S9. Generation of superoxide radicals $\cdot \mathrm{O}_{2}-$

S10. Analysis of $\mathrm{O}_{2}$ consumption/generation.

S11. Cell culture conditions and study of CuFe cytotoxicity.

S12. References.

Figure S1. DOSY spectra of GSH GSSG standards. 32

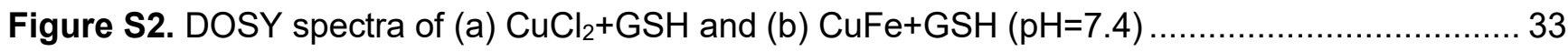

Figure S3. ${ }^{1} \mathrm{H}-\mathrm{NMR}-\mathrm{DOSY}$ analysis from $\mathrm{FeCl}_{3}+\mathrm{GSH}$ experiments. .......................................... 34

Figure S4. HRMS-ESI analysis of different species found in $\mathrm{FeCl}_{3}+\mathrm{GSH}$ mixture........................ 35

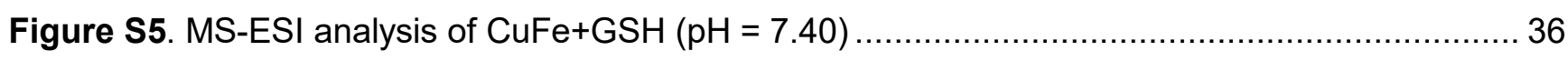

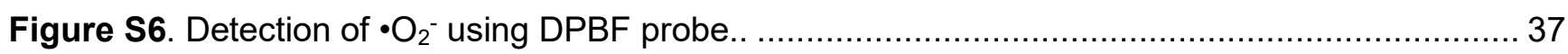

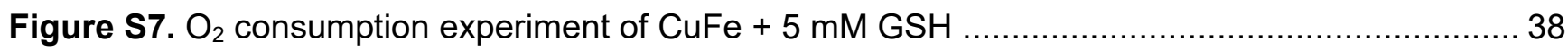

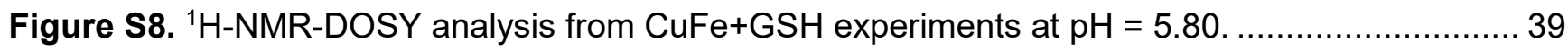

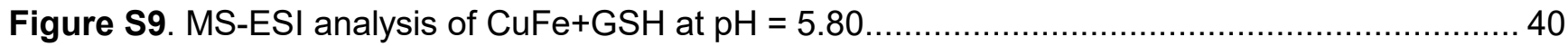

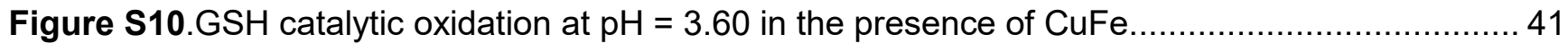

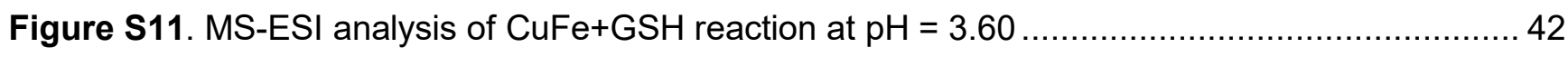

Figure S12. XRD pattern obtained from CuFe after reaction with $5 \mathrm{mM}$ of $\mathrm{GSH}$....................... 43

Figure S13. $\cdot \mathrm{OH}$ generation experiment of Fe-enriched catalyst ......................................... 44

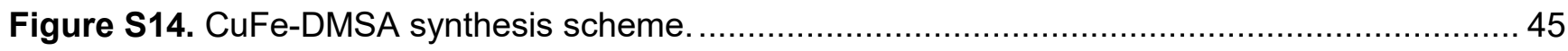

Figure S15. Size distribution of CuFe after/before DMSA functionalization ................................ 46

Table S1. Elemental composition of CuFe surface measured by XPS before GSH reaction.

Table S2. XPS quantification of the different Fe and Cu species present on the catalyst surface before reaction with $\mathrm{GSH}$. 47

Table S3. Elemental composition of CuFe surface measured by XPS after GSH reaction. 47

Table S4. XPS quantification of the different Fe and Cu species present on the catalyst surface after reaction with $\mathrm{GSH} .$.

Table S5. GSH standards composition employed to analyze GSH-catalytic experiments. 48 
S1. Chemicals and Materials. Iron (III) chloride hexahydrate $\left(\mathrm{FeCl}_{3} \cdot 6 \mathrm{H}_{2} \mathrm{O}, 97 \%\right)$, copper (II) chloride dihydrate $\left(\mathrm{CuCl}_{2} \cdot 2 \mathrm{H}_{2} \mathrm{O}, \geq 99.0 \%\right)$, sodium acetate anhydrous $\left(\mathrm{CH}_{3} \mathrm{COONa}\right.$, $99.0 \%$ ), Bovine Serum Albumin (BSA), ethylene glycol (EG), Dimercaptosuccinic Acid (DMSA, $99.0 \%$ ), Glutathione, Glutathione oxidized (GSSG, $\geq 98.0 \%$ HPLC), 5,5'-Dithiobis(2nitrobenzoic acid) (DNTB), hydrogen peroxide $\left(\mathrm{H}_{2} \mathrm{O}_{2}, 33 \% \mathrm{v} / \mathrm{v}\right)$, sodium bicarbonate $\left(\mathrm{NaHCO}_{3}\right.$, 99\%), Methylene Blue (MB, $\geq 95.0$ ) were purchased from Sigma Aldrich.. Acetonitrile (ACN) was purchased from WVR (Avantor). UPLC grade water was obtained from a Milli-Q Advantage A10 System with resistivity of $18.2 \mathrm{~m} \Omega$ (Merk Millipore, Germany).

S2. Characterization techniques. Transmission electron microscopy (TEM) was performed using a FEI TECNAI T20 microscope operated at $200 \mathrm{keV}$. High-resolution transmission electron microscopy (HRTEM) was performed using a FEI Titan (80-300 kV) microscope at an acceleration voltage of $300 \mathrm{kV}$. In both cases samples were prepared by drop casting $5 \mu \mathrm{L}$ of the nanoparticle suspension on a holey carbon TEM grid. UV-vis spectra were obtained on a UV-vis double beam spectrophotometer Jasco V67. X-ray photoelectron spectroscopy (XPS) was performed with an Axis Supra spectrometer (Kratos Tech). The samples were mounted on a sample rod placed in the pretreatment chamber of the spectrometer and then evacuated at room temperature. The spectra were excited by a monochromatized Al Ka source at $1486.6 \mathrm{eV}$ and subsequently run at $8 \mathrm{kV}$ and $15 \mathrm{~mA}$. A survey spectrum was measured at $160 \mathrm{eV}$ of pass energy, and for the individual peak regions, spectra were recorded with a pass energy of $20 \mathrm{eV}$. Analysis of the peaks was performed with the CasaXPS software using a weighted sum of Lorentzian and Gaussian component curves after Shirley background subtraction. The binding energies were referenced to the internal $C$ is standard at $284.5 \mathrm{eV}$. X-ray diffraction patterns were obtained in a PANalytical Empyrean equipment in Bragg-Brentano configuration using CuKa radiation and equipped with a PIXcel1D detector. ${ }^{1} \mathrm{H}$ spectra $\left(\mathrm{D}_{2} \mathrm{O}\right)$ were recorded at $25{ }^{\circ} \mathrm{C}$ using a Bruker Avance $400 \mathrm{MHz}$ NMR spectrometer with TMS as the internal standard and deuterated water as solvent in a $5 \mathrm{~mm}$ QNP probe. Nanoparticle Tracking Analysis was measured on Malvern Nanosight 300.

\section{S3. Synthesis of CuFe-DMSA nanoparticles. $\mathrm{CuFe}_{2} \mathrm{O}_{4}$ nanoparticles}

were synthesized via templated-growth method. Firstly, $250 \mathrm{mg}$ of BSA were dissolved in $2.5 \mathrm{~mL}$ of miliQ water and consequently $12.5 \mathrm{~mL}$ of Ethylene glycol were added. After that, $270.0 \mathrm{mg}$ of $\mathrm{FeCl}_{3} \cdot 6 \mathrm{H}_{2} \mathrm{O}, 85.0 \mathrm{mg}$ of $\mathrm{CuCl}_{2}$ and $375.0 \mathrm{mg}$ of $\mathrm{CH}_{3} \mathrm{COONa}$ were added into the reaction vessel. Reaction was left to stir $2 \mathrm{~h}$ at room temperature to ensure a correct binding of BSAnucleophile groups to the metallic ions. Then, the reaction was transferred to a Teflon autoclave 
and the temperature was set to $180^{\circ} \mathrm{C}$ for $24 \mathrm{~h}$. Finally, the product was centrifuged at 12000 rpm for $20 \mathrm{~min} .20 \mathrm{~mL}$ of a $25 \mathrm{mM}$ solution of DMSA were poured to the reaction pellet and the dispersion was assisted with ultrasonication. $5 \mathrm{~mL}$ of $0.7 \mathrm{M} \mathrm{NaOH}$ solution were added to ensure the correct DMSA dissolution to decorate the nanocatalyst surface. The final product was purified by two centrifugation cycles at $12000 \mathrm{rpm}$ for $20 \mathrm{~min}$. The nanocatalyst was stored at $4^{\circ} \mathrm{C}$ for further use. CuFe nanocatalysts were synthetized using Bovine Serum Albumin (BSA) as template ${ }^{1,2}$ and Ethylene glycol (EG) as a solvent to modulate particle size ${ }^{3}$. The abundance of nucleophile functional groups in the BSA (-COO-, $\left.-\mathrm{NH}_{2}\right)$ can chelate the metal ions $\left(\mathrm{Cu}^{2+}\right.$, $\mathrm{Fe}^{3+}$ ) and serve as starting point to growth the nanostructure. Although the distribution size of the nanoparticles is homogeneous, these nanoparticles suffer from aggregation in aqueous media, which may hinders cell internalization ${ }^{4}$. As shown previously by Miguel-Sancho et al. ${ }^{5}$, DMSA functionalization enhanced the dispersion and stability of the nanoparticles in aqueous media (Fig. S14-15). The synthesis of these materials has been performed at the Platform of Production of Bio-materials and Nanoparticles of the NANBIOSIS ICTS, more specifically by the Nanoparti-cle Synthesis Unit of the CIBER in BioEngineering, Biomaterials \& Nanomedicine (CIBER-BBN).

\section{S4. Metal leaching study by Microwave Plasma-Atomic Emission Spectroscopy (MP-AES). Each solution was prepared in an} eppendorf tube with CuFe-DMSA nanoparticle at a concentration of $0.1 \mathrm{mg} / \mathrm{mL}$ (total volume $=1$ $\mathrm{mL}$ ). The different solutions were introduced in an Eppendorf thermoshaker at $37^{\circ} \mathrm{C}$ and constant stirring of $400 \mathrm{rpm}$. At every time point ( $2 \mathrm{~h}, 4 \mathrm{~h}, 6 \mathrm{~h} 24 \mathrm{~h})$, samples were centrifuged at 13300 rpm during 30', and the supernatants were collected for further analysis. The nanoparticle pellet was resuspended with the corresponding solution, until the next analysis cycle, where the procedure was repeated. At the experiment endpoint, the supernatant samples were analyzed together with final nanoparticle pellet, to close mass balances and elucidate how much metal moved to the solution. All the samples were digested with $\mathrm{HCl}: \mathrm{HNO}_{3}(3: 1)$ mixture overnight. $\mathrm{Cu}$ and $\mathrm{Fe}$ concentrations were determined through the analysis with Agilent 4100 MP-AES.

S5. ${ }^{1} \mathrm{H}-\mathrm{NMR}$-study of CuFe-GSH interaction. The interaction study of leached metals $(\mathrm{Cu}, \mathrm{Fe})$ with $\mathrm{GSH}$ was performed by the ${ }^{1} \mathrm{H}-\mathrm{NMR}$ and DOSY analysis of different reaction mixtures. For $\mathrm{CuCl}_{2}$-GSH experiments, the $\mathrm{pH}$ was fixed to 7.4 (buffer $\left.\mathrm{Na}_{2} \mathrm{HPO}_{4} / \mathrm{KH}_{2} \mathrm{PO}_{4}\right)$ and the molar ratio $\mathrm{CuCl}_{2}: \mathrm{GSH}$ was set to $1: 4 \quad$ ([GSH]=20mM, $\left[\mathrm{CuCl}_{2} \cdot 2 \mathrm{H}_{2} \mathrm{O}\right]=5 \mathrm{mM}$. For $\mathrm{FeCl}_{3}-\mathrm{GSH}$ experiments, the $\mathrm{pH}$ was not fixed $(\mathrm{pH}=3.60)$ and the molar ratio $\mathrm{FeCl}_{3}: \mathrm{GSH}$ was set to $1: 4$ ([GSH]=20mM, $\left.\left[\mathrm{FeCl}_{3} \cdot 6 \mathrm{H}_{2} \mathrm{O}\right]=4 \mathrm{mM}\right)$. The reaction mixtures were analyzed after incubation for 5 minutes. For CuFe+GSH experiments, molar ratio 
CuFe:GSH was 1:44 ([GSH] $\left.=20 \mathrm{mM},\left[\mathrm{CuFe}_{2} \mathrm{O}_{4}\right]=0.5 \mathrm{mM}\right)$. Reaction were incubated at $\mathrm{pH}=7.4$ $\left(\mathrm{Na}_{2} \mathrm{HPO}_{4} / \mathrm{KH}_{2} \mathrm{PO}_{4}\right)$ and $\mathrm{pH}=3.70($ free $\mathrm{pH})$ for 3 and $24 \mathrm{~h}$. All samples were filtered before analysis.

S6. Mass spectroscopy analysis of the reaction. ESI (ESI+) mass spectra were recorded using an Esquire 3000 ion-trap mass spectrometer (Bruker Daltonic $\mathrm{GmbH}$ ) equipped with a standard ESI/APCI source. Samples were introduced by direct infusion with a syringe pump. Nitrogen served both as the nebulizer gas and the dry gas. The HRMS mass spectra were recorded using an MicroToF Q, API-Q-ToF ESI with a mass range from 20 to $3000 \mathrm{~m} / \mathrm{z}$ and mass resolution 15000 (FWHM). Samples prepared for ${ }^{1} \mathrm{H}-\mathrm{NMR} / \mathrm{DOSY}$ experiments were analyzed by using this methodology.

S7. Catalytic GSH depletion. Catalytic activity towards GSH oxidation of CuFeDMSA nanoparticles was evaluated according to the following protocol. $5 \mathrm{mM}$ of $\mathrm{GSH}$ were mixed with $0.1 \mathrm{mg} \cdot \mathrm{mL}^{-1}$ of CuFe-DMSA in a total volume of $2.5 \mathrm{~mL}$. GSH concentration at different reaction times was measured by UPLC-PDA. $20 \mu \mathrm{L}$ of reaction were mixed with $100 \mu \mathrm{L}$ of 5,5'-Disulfanediylbis(2-nitrobenzoic acid) (DTNB) and $880 \mu \mathrm{L}$ of $0.01 \mathrm{M}$ 2-Amino-2hydroxymethyl-propane-1,3-diol (TRIS).

\section{S8. UPLC-PDA equipment for GSH quantification. GSH analysis} were performed on Waters ACQUITY system H-Class which consisted of a binary pump, an autosampler, a column thermostat and a photodiode array (PDA) detector. This system is coupled to a PhotoDiode Array (PDA) detector to monitor absorbance from derivatized GSH at $412 \mathrm{~nm}$ during analysis time. Data acquisition and processing were performed by using MASSLYNX software (Waters Corporation USA). In order to analyze GSH from derivatized samples as describe below, chromatographic separation was performed using an ACQUITY UPLC BEH C18 column (130 A, $1.7 \mu \mathrm{m} 2.1 \times 50 \mathrm{~mm}$, from WATERS ) at $40^{\circ} \mathrm{C}$ under an isocratic flow of $0.3 \mathrm{~mL} \cdot \mathrm{min}^{-1}$ containing $50 \%$ acetonitrile, $50 \%$ milli $Q$ water.

\section{S9. Generation of superoxide radicals $\bullet^{\mathbf{O}_{2}} \cdot \mathbf{1}, 1$-Diphenylisobenzofuran}

(DPBF) was employed as a probe to measure the production of $\cdot \mathrm{O}_{2}$ - during homogeneous $\mathrm{GSH}$ oxidation. $20 \mu \mathrm{L}$ of $10 \mathrm{mM}$ DPBF solution (in Ethanol) were added to $2.5 \mathrm{~mL}$ of a mixture Ethanol:PBS(X1) 2:1. Catalyst and $\mathrm{GSH}$ concentration were $0.1 \mathrm{mg} \cdot \mathrm{mL}^{-1}$ and $5 \mathrm{mM}$, respectively. UV-vis analysis of remaining DPBF was performed after centrifuging the sample $(100 \mu \mathrm{L}$ of reaction $+400 \mu \mathrm{L}$ mixture Ethanol:PBSX1) at $13000 \mathrm{rpm}$ for 5 '. 


\section{S10. Analysis of $\mathrm{O}_{2}$ consumption/generation. Molecular oxygen was}

measured with a NeoFox oximeter equipped with FOSPOR-R probe. In order to analyze the $\mathrm{O}_{2}$ generation capabilities of the remaining nanoparticle, CuFe $\left(0.1 \mathrm{mg} \cdot \mathrm{mL}^{-1}\right)$ was incubated with 5 $\mathrm{mM}$ of $\mathrm{GSH}(\mathrm{pH}=7.40)$ for $3 \mathrm{~h}$ to induce selective Cu-release. The solution was centrifuged at $13300 \mathrm{rpm}$ for $10^{\prime}$ to separate homogeneous and heterogeneous catalysts to analyze their individual catalytic activity towards $\mathrm{O}_{2}$ production using $\left[\mathrm{H}_{2} \mathrm{O}_{2}\right]_{0}=1 \mathrm{mM}$.

\section{S11. Cell culture conditions and study of CuFe cytotoxicity.}

In order to assess the effect that these nanoparticles produced on the chosen cell lines, a viability assay on 96 well plates was carried out. Briefly, cells were seeded at different densities depending on their type (3000 cells/well for tumoral cell lines, i.e. U251-MG, SKOV1, HeLa, U87-MG and 4000 cells/well for healthy cell lines, i.e. hpMSC and fibroblasts), using Dulbecco's Modified Eagle Medium (DMEM), supplemented with 1\% L-Glutamine, 1\% PSA (Penicillin, Streptomycin, Amphotericin), and 10\% Fetal Bovine Serum (FBS); in the case of hpMSC, DMEM medium was also supplemented with Fibroblast Growth Factor 2 (FGF-2) at $5 \mu \mathrm{g} / \mathrm{mL}$.

$24 \mathrm{~h}$ after the seeding, the wells were treated with CuFe nanoparticles, in such a way that the supernatant in each well was replaced with a suspension of CuFe nanoparticles in DMEM (DMEM + FGF-2 for hpMSC) at different concentrations, ranging from 0.2 to $0.0125 \mathrm{mg} / \mathrm{mL}$.

After 24,48 and $72 \mathrm{~h}$ of incubation, the wells were washed with Dulbecco's Phosphate Buffered Saline (DPBS), and then, a solution of Blue Cell Viability Reagent in DMEM (10\% $\mathrm{v} / \mathrm{v}$ ) was used to assess the cytotoxic effect of these nanoparticles on the different cell lines. After $1 \mathrm{~h}$ of incubation with the Blue Cell Viability Reagent at $37^{\circ} \mathrm{C}$, the signal was measured with a BioTek plate reader, exciting at $528 \mathrm{~nm}$ and measuring the emission at $590 \mathrm{~nm}$. 


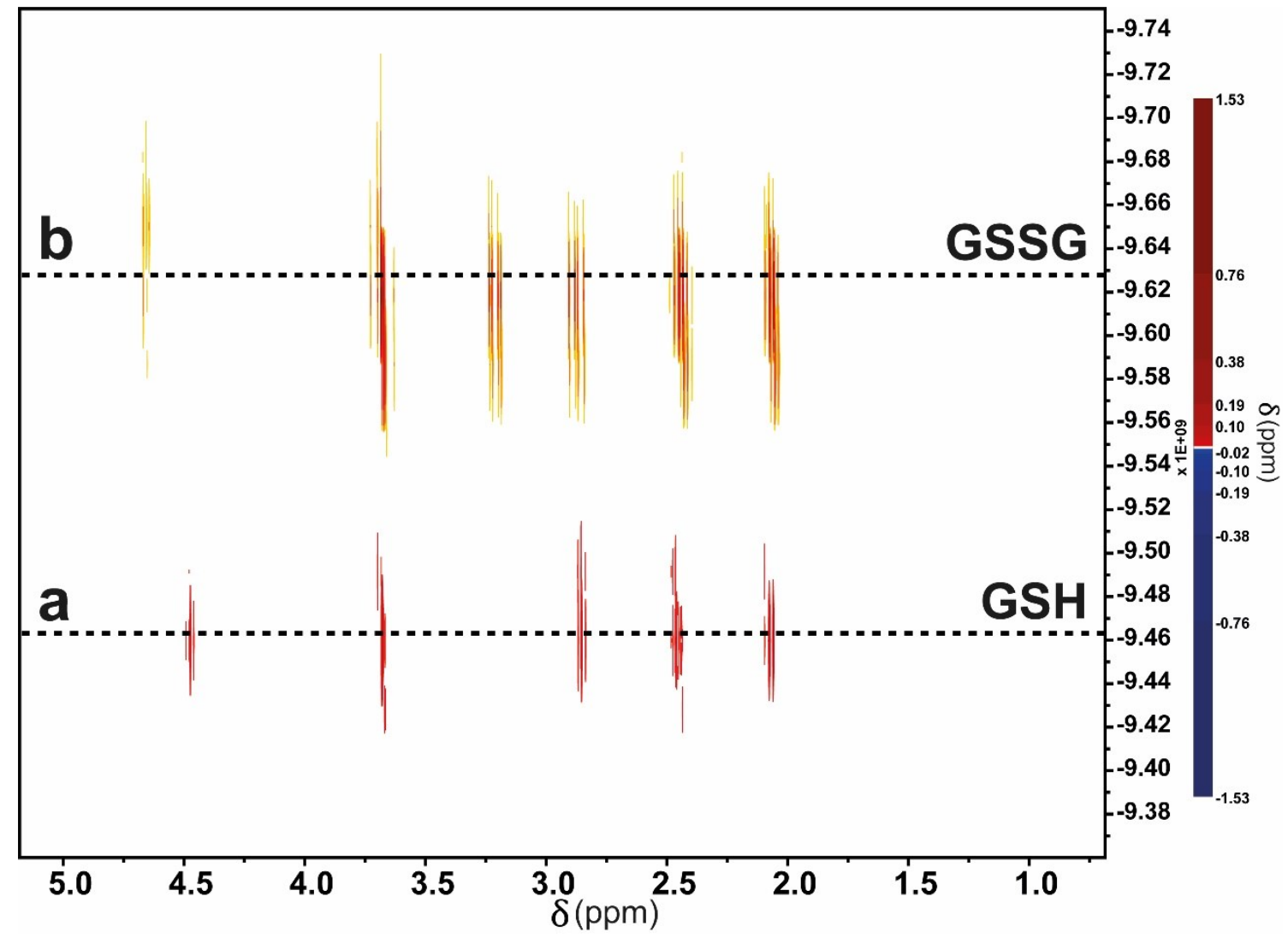

Figure S1. DOSY spectra of (a) GSH (down) and (b) GSSG (top) standards. Molecular size differences between reduced (GSH) and oxidized GSH (GSSG) translate into different diffusion coefficients $(D)$ of the molecule. Following this trend, determined $D$ for GSH is larger in comparison to GSSG. 


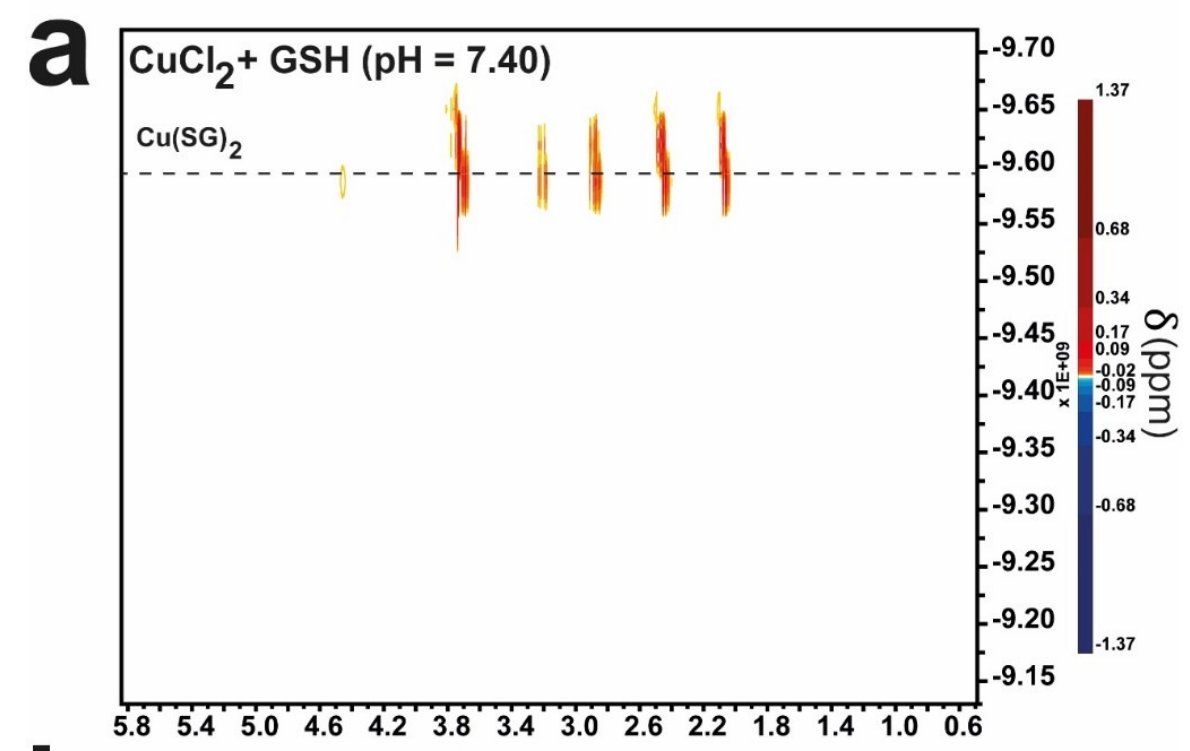

b

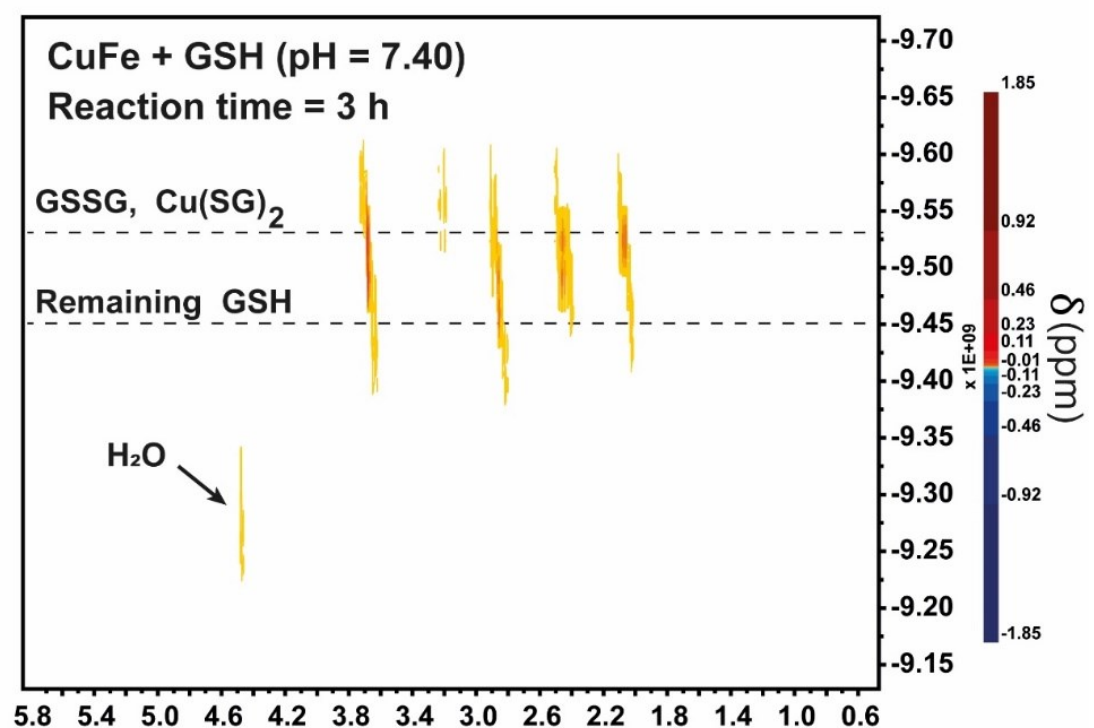

Figure S2. Comparison of diffusion coefficients of (a), $\mathrm{CuCl}_{2}+\mathrm{GSH}$ (red) and (b) CuFe+GSH (3h) (purple). Reaction conditions $[\mathrm{GSH}]=20 \mathrm{mM}, \mathrm{pH}=7.0\left(\mathrm{HPO}_{4}{ }^{2-}\right.$ $\left./ \mathrm{H}_{2} \mathrm{PO}_{4}\right), \mathrm{T}=25^{\circ} \mathrm{C}$, reaction time $=3 \mathrm{~h}$. (a) DOSY spectra corresponding to the mixture $\mathrm{CuCl}_{2}+\mathrm{GSH}$ indicate the generation of $\mathrm{Cu}(\mathrm{SG})_{2}$ complex and GSSG, which possess a similar molecular size and therefore a similar D is obtained. (b) DOSY spectra of $\mathrm{CuFe}+\mathrm{GSH}$ reaction at $\mathrm{pH}=7.40$ at $3 \mathrm{~h}$. As reaction is not over at this time, some remaining GSH appears at low D values (highlighted in dashed line). Moreover, as $\mathrm{GSH}$ and $\mathrm{GSSG} / \mathrm{Cu}(\mathrm{SG})_{2}$ possess same signals for some $H(\delta=3.70 \mathrm{ppm}, \delta=2.85$ ppm, $\delta=2.45 \mathrm{ppm}$ and $\delta=2.05 \mathrm{ppm}$ ), DOSY signals appear wider. A similar signal with a calculated $D$ of $4.00 \cdot 10^{-10} \mathrm{~m}^{2} \cdot \mathrm{s}^{-1}$ in comparison with $\mathrm{CuCl}_{2}+\mathrm{GSH}$ mixture is obtained under conditions that favour leaching of $\mathrm{Cu}$, suggesting the formation of $\mathrm{Cu}(\mathrm{SG})_{2}$ complex in situ using the Cu released from the nanoparticle. 


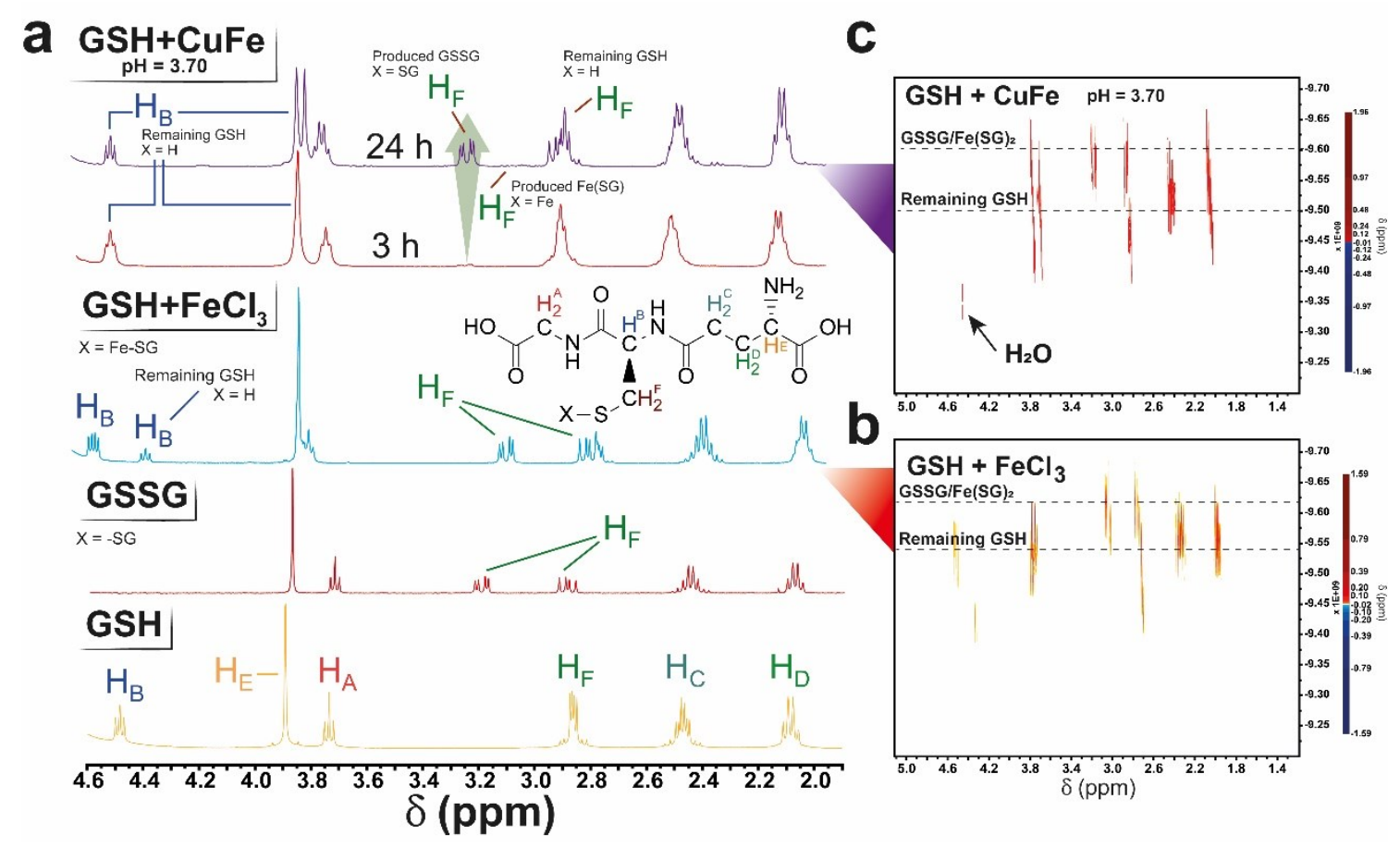

Figure S3. (a) ${ }^{1} \mathrm{H}-\mathrm{NMR}$ analysis from $\mathrm{FeCl}_{3}+\mathrm{GSH}$ experiments. Generation of $\mathrm{Fe}-\mathrm{SG}$ complex entails the splitting of HF signals at 3.04 and $2.76 \mathrm{ppm}$. Analysis of reaction supernatant at $3 \mathrm{~h}$ reveals a small amount of GSSG produced in comparison with $\mathrm{CuFe}+\mathrm{GSH}$ at $\mathrm{pH}=7.40$ consequence of slower reaction kinetics of Fe-homogeneous catalysis of GSH oxidation. However, after $24 \mathrm{~h}$ of reaction, a larger amount of Cu has been released and the reaction rate increases; (b) DOSY analysis of $\mathrm{GSH}+\mathrm{FeCl}_{3}$ mixture reveals the formation of a product with a D close to GSSG, while an important amount of GSH is still present in the solution (confirmed by ${ }^{1} \mathrm{H}-\mathrm{NMR}$ in Fig. S3a). (c) DOSY spectra of $\mathrm{CuFe}+\mathrm{GSH}$ at $\mathrm{pH}=3.70$ 


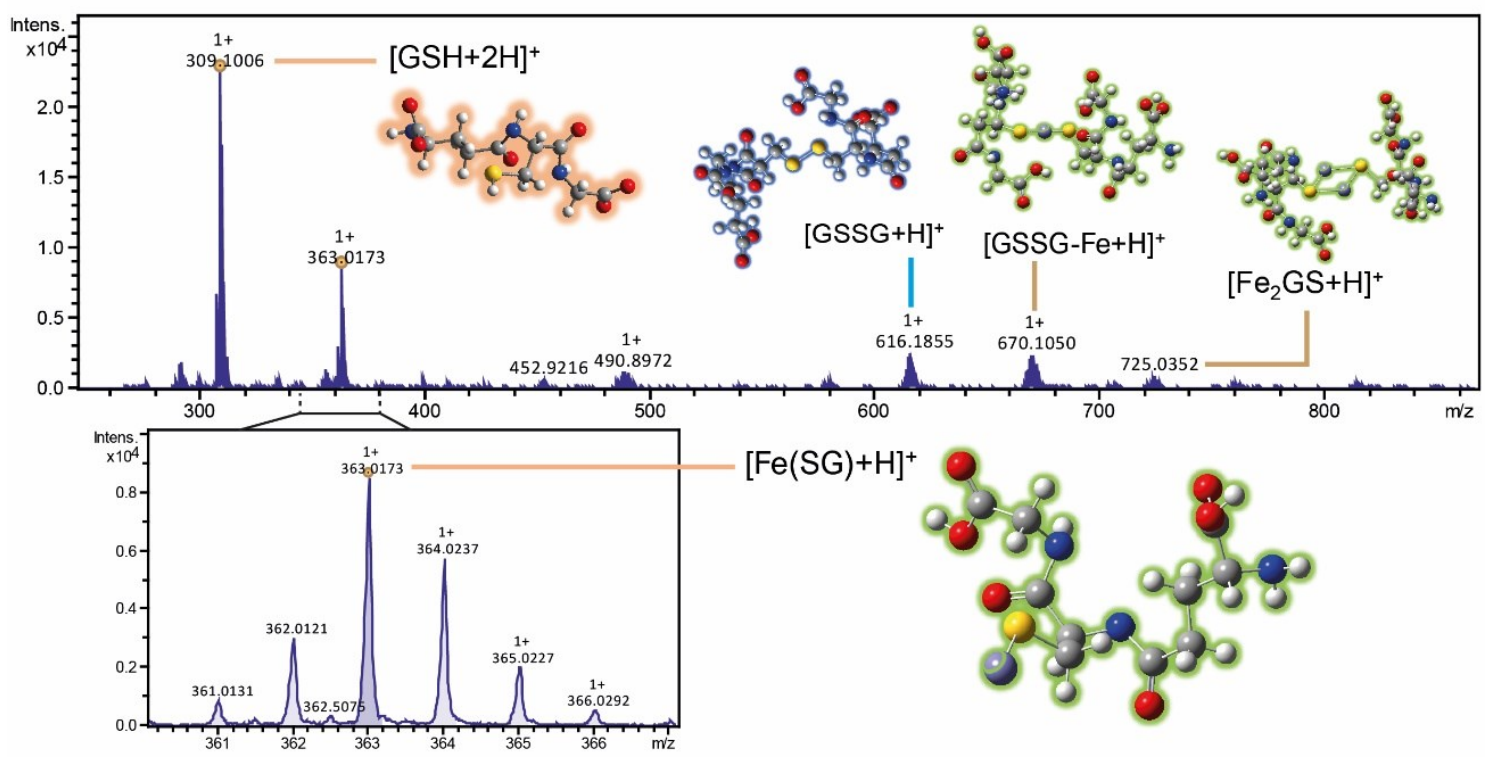

Figure S4. HRMS-ESI analysis of different species found in $\mathrm{FeCl}_{3}+\mathrm{GSH}$ mixture $(\mathrm{pH}=3.60)$. Remaining $\mathrm{GSH}$ is found at $\mathrm{m} / \mathrm{z}=309.1006\left([\mathrm{GSH}+\mathrm{H}]^{+}\right)$, which is consistent with an important fraction of GSH still present in the solution detected by ${ }^{1} \mathrm{H}-$ NMR (Fig. S3). [Fe(SG) $]$ complexes are detected at $\mathrm{m} / \mathrm{z}=363.0173\left([\mathrm{Fe}(\mathrm{SG})+\mathrm{H}]^{+}\right)$ and $\mathrm{m} / \mathrm{z}=670.1050\left([\mathrm{Fe}(\mathrm{GSSG})+\mathrm{H}]^{+}\right.$Polynuclear species are also detected at 725.0352 $\left(\left[(\mathrm{Fe}(\mathrm{SG}))_{2}+\mathrm{H}\right]^{+}\right.$. 


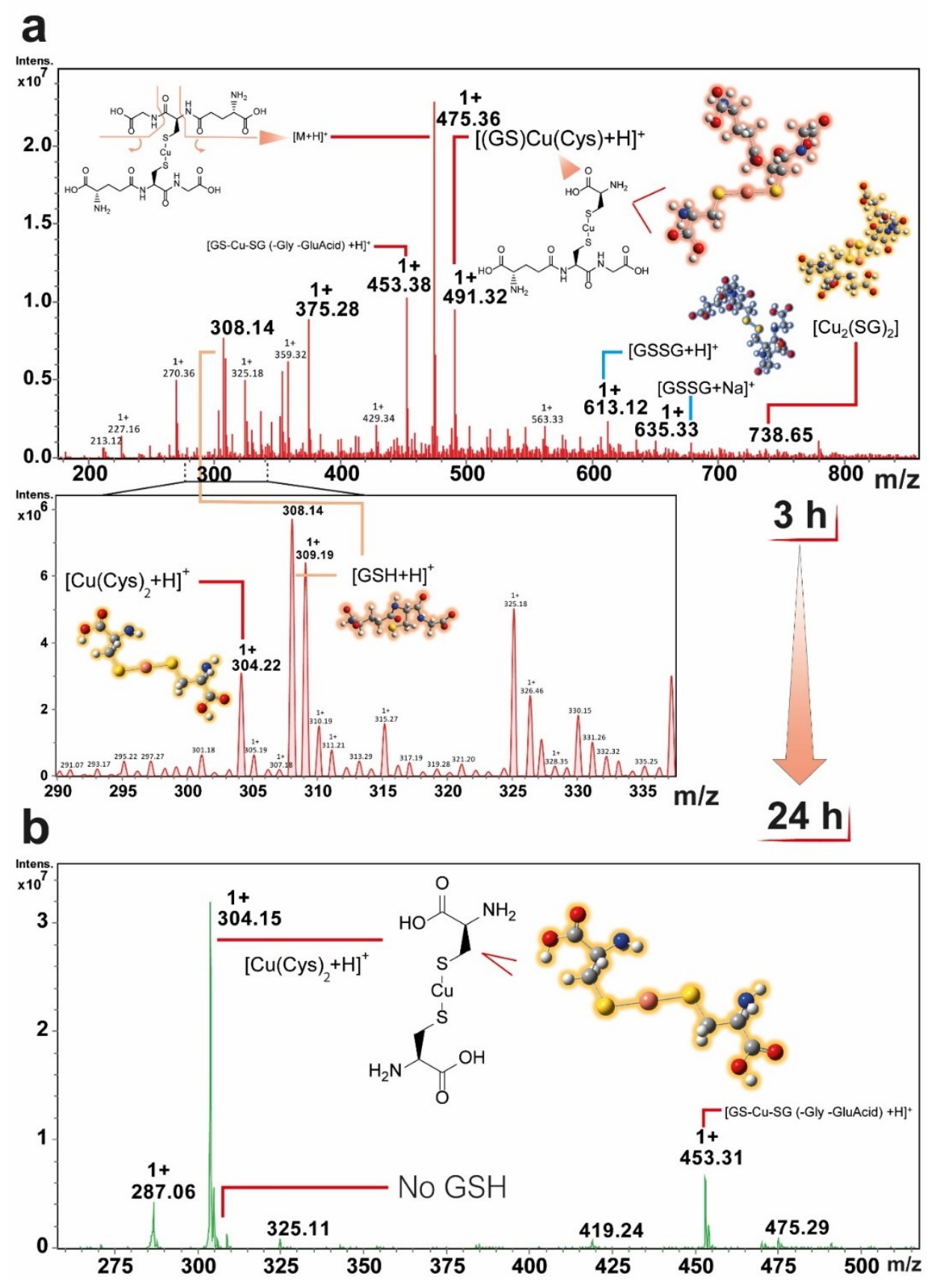

Figure S5. MS-ESI analysis of CuFe+GSH $(\mathrm{pH}=7.40)$ at different reaction times: (a) $3 \mathrm{~h}$ and (b) $24 \mathrm{~h}$. After 3 hours of reaction unreacted GSH and reaction product, GSSG signals at $\mathrm{m} / \mathrm{z}=308$ and $\mathrm{m} / \mathrm{z}=613$ are present in the spectra, in agreement with ${ }^{1} \mathrm{H}$ NMR results. Different fragments from the $\left[\mathrm{Cu}(\mathrm{SG})_{2}\right]+$ complex were found at $\mathrm{m} / \mathrm{z}=$ 491.32 ([Cu(SG)(Cys) $\left.]^{+}\right), 453.38$ ([Cu(SG)(SG)-Glutamic Acid-Glycine $]^{+}$) and 304.27 $\left[\mathrm{Cu}(\mathrm{Cys})_{2}\right]^{+}$, with the $\mathrm{Cu}-\mathrm{S}$ bond always present. Analysis of the reaction supernatant at reaction time $24 \mathrm{~h}$ revealed the total consumption of $\mathrm{GSH}$, according to ${ }^{1} \mathrm{H}-\mathrm{NMR}$ analysis and the prominence of the $\left[\mathrm{Cu}(\mathrm{Cys})_{2}\right]^{+}$fragment. We assume that the nanoparticle affects to the MS fragmentation pattern, as we were not able to detect those fragments by ${ }^{1} \mathrm{H}-\mathrm{NMR}$. 


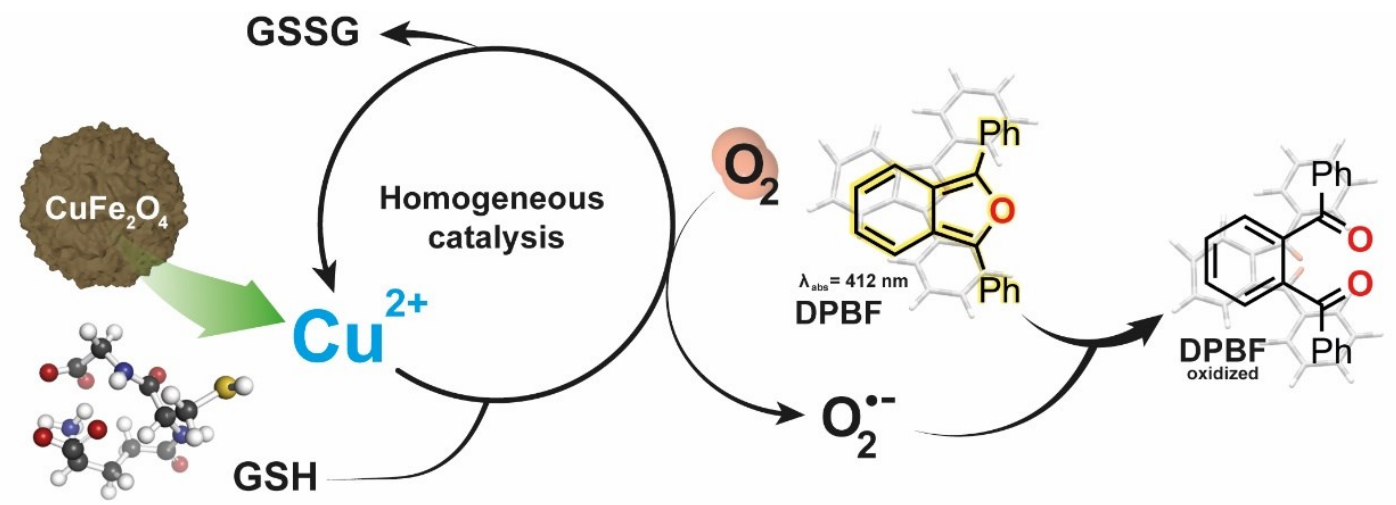

Figure S6. Detection of $\cdot \mathrm{O}_{2}^{-}$using DPBF probe. In the presence of $\mathrm{GSH}, \mathrm{Cu}^{2+}$ is released to the media and homogeneous oxidation of $\mathrm{GSH}$ occur. $\cdot \mathrm{O}_{2}{ }^{-}$is produced in the process and preferentially oxidizes DPBF, which absorbs at $412 \mathrm{~nm}$, to $1,2-$ dibenzoylbenzene, a colorless molecule. 


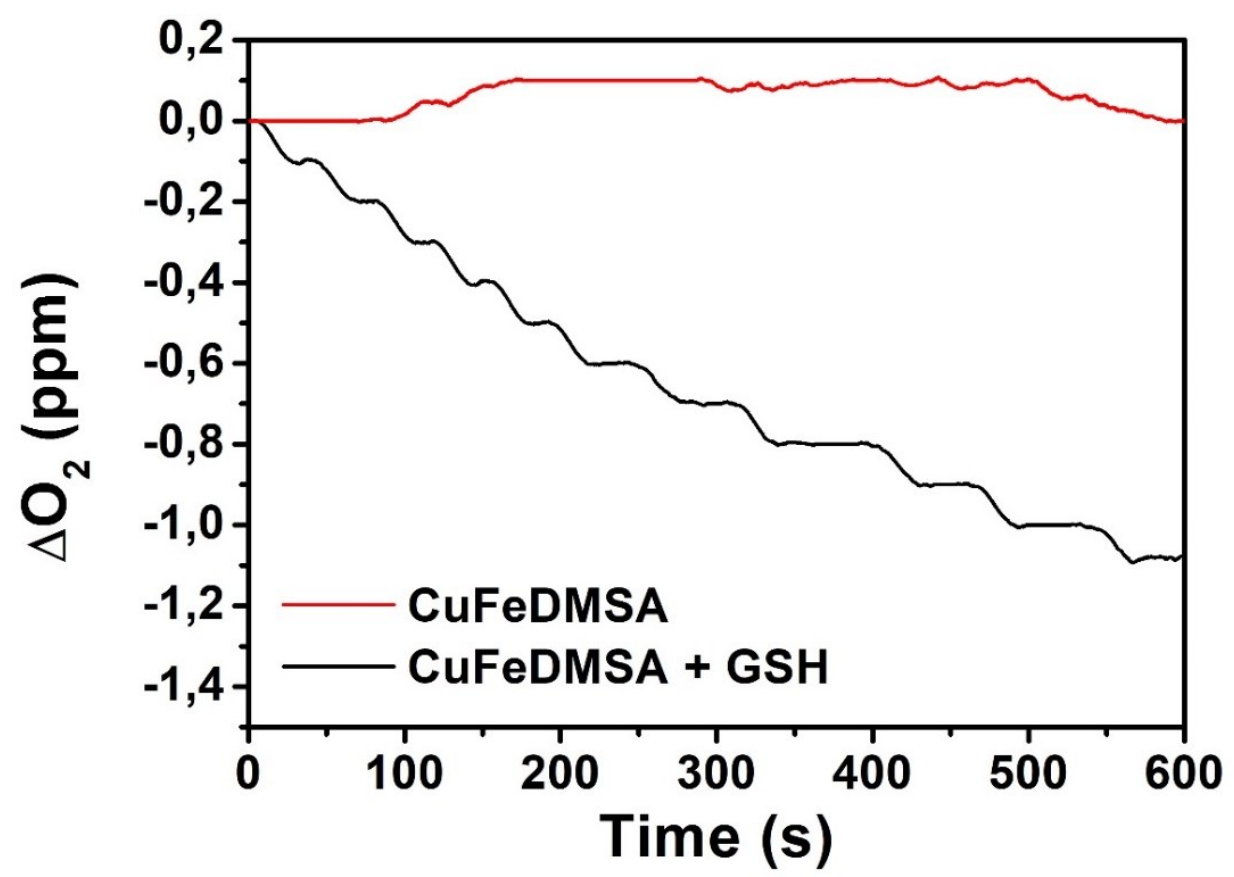

Figure S7. $\mathrm{O}_{2}$ consumption in the presence of CuFe with or without the addition of 5 $\mathrm{mM} \mathrm{GSH}$. [CuFe] $=0.1 \mathrm{mg} \cdot \mathrm{mL}^{-1}, \mathrm{pH}=7.40$ (adjusted with $\mathrm{HPO}_{4}{ }^{2-} / \mathrm{H}_{2} \mathrm{PO}_{4}{ }^{-}$). The decrease of $\mathrm{O}_{2}$ levels in solution once CuFe and GSH are mixed corresponds to its role as electron acceptor in the homogeneous GSH oxidation. 


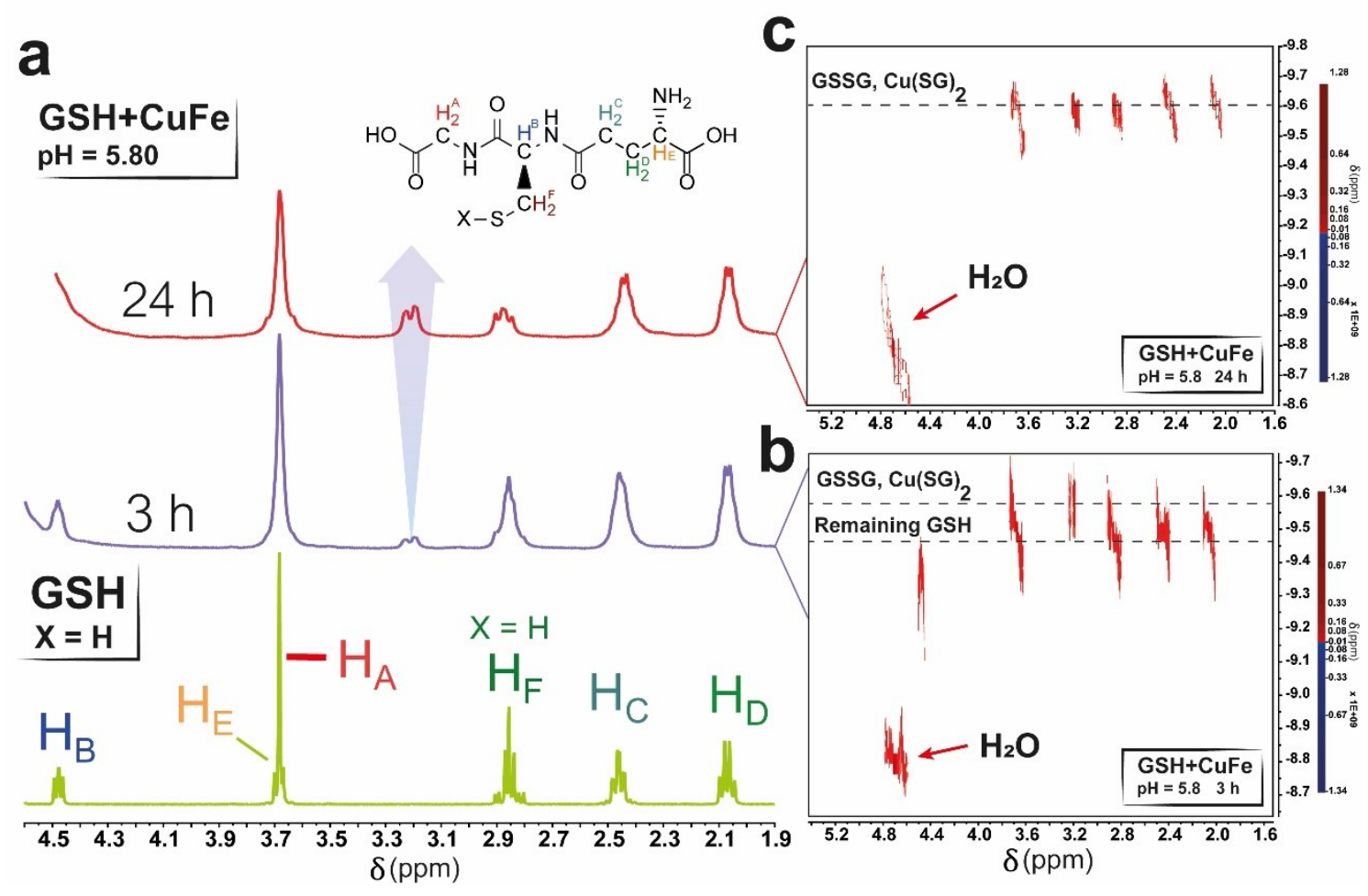

Figure S8. (a) ${ }^{1} \mathrm{H}-\mathrm{NMR}$ analysis from $\mathrm{CuFe}+\mathrm{GSH}$ experiments at $\mathrm{pH}=5.80$. A similar behavior in comparison with $\mathrm{CuFe}+\mathrm{GSH}$ at $\mathrm{pH}=7.40$ is found at tumor-characteristic $\mathrm{pH}$. After $3 \mathrm{~h}$ of reaction, a characteristic signal of $\mathrm{GSSG} / \mathrm{Cu}(\mathrm{SG})_{2}$ at $3.22 \mathrm{ppm}$ appears as consequence of modification of $-\mathrm{CH}_{2}$ - close to $-\mathrm{SH}$ group. The reaction is complete after $24 \mathrm{~h}$, as no signal of GSH is present at $4.5 \mathrm{ppm}$. (b) DOSY spectra of GSH+CuFe mixture at $\mathrm{pH}=5.80\left(\mathrm{HPO}_{4}{ }^{2-} / \mathrm{H}_{2} \mathrm{PO}_{4}^{-}\right)$, presenting both signals from $\mathrm{GSH}$ and GSSG/Cu(SG) $)_{2}$ (c) DOSY spectra of $\mathrm{GSH}+\mathrm{CuFe}(\mathrm{pH}=5.8)$ after $24 \mathrm{~h}$ of reaction, with the signal of GSH disappeared. Molecular species with a D similar to GSSG/Cu(SG) 2 are detected after $24 \mathrm{~h}$ of reaction. 

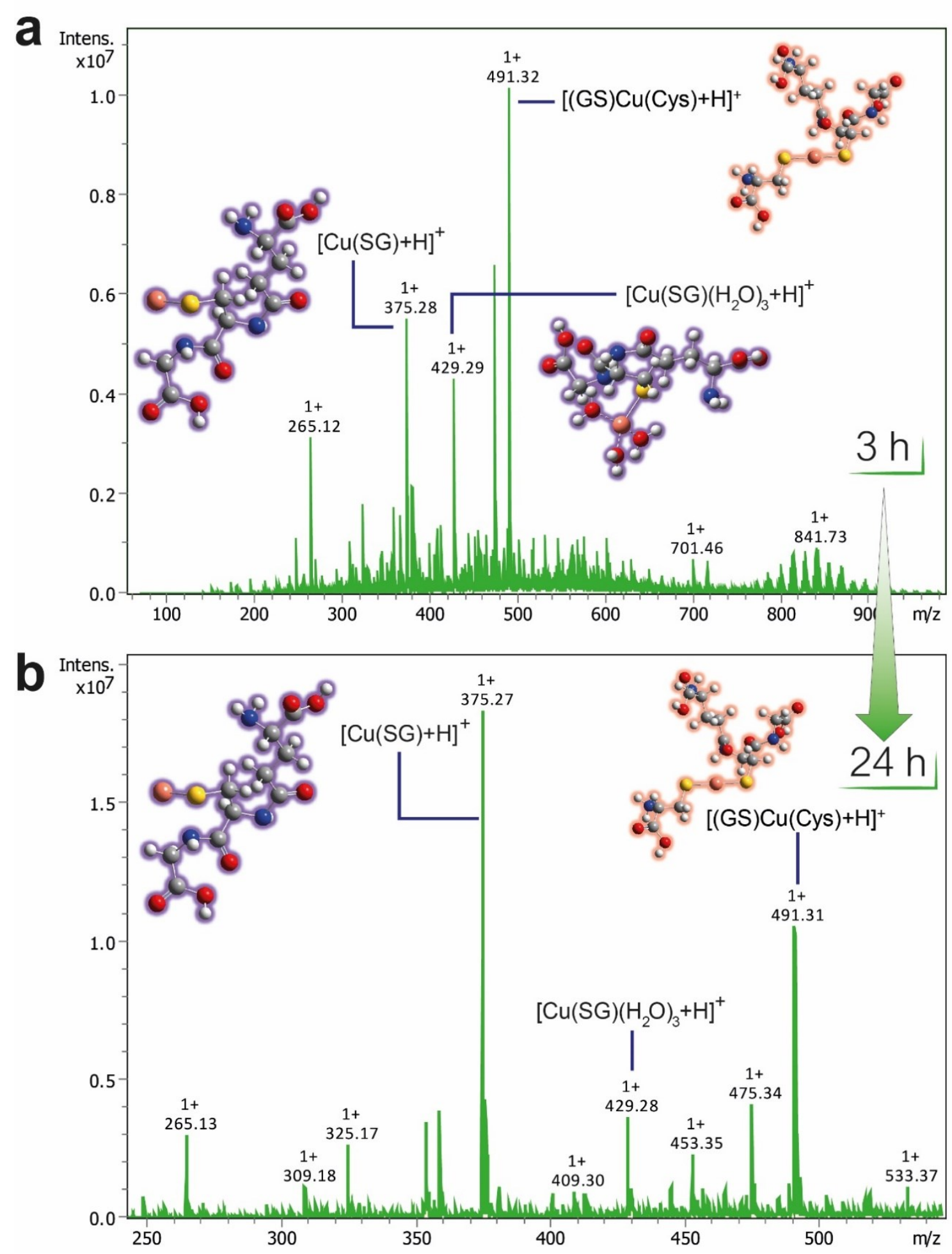

Figure S9. MS-ESI analysis of CuFe+GSH $(\mathrm{pH}=5.80)$ at reaction time (a) $3 \mathrm{~h}$ and $(\mathrm{b})$ 24h. $\left[\mathrm{Cu}(\mathrm{SG})_{2}\right]^{+}$-derived fragments are present at $\mathrm{m} / \mathrm{z}=375.28\left([\mathrm{Cu}(\mathrm{SG})+\mathrm{H}]^{+}\right), 429.29$ $\left(\left[\mathrm{Cu}(\mathrm{SG})\left(\mathrm{H}_{2} \mathrm{O}\right)_{3}+\mathrm{H}\right]^{+}\right)$and $491\left([\mathrm{Cu}(\mathrm{SG})(\mathrm{Cys})+\mathrm{H}]^{+}\right.$. Analysis of the reaction supernatant at reaction time $24 \mathrm{~h}$ revealed the total consumption of $\mathrm{GSH}$, according to ${ }^{1} \mathrm{H}-\mathrm{NMR}$ analysis and the prominence of a $[\mathrm{Cu}(\mathrm{SG})]$ fragment. 


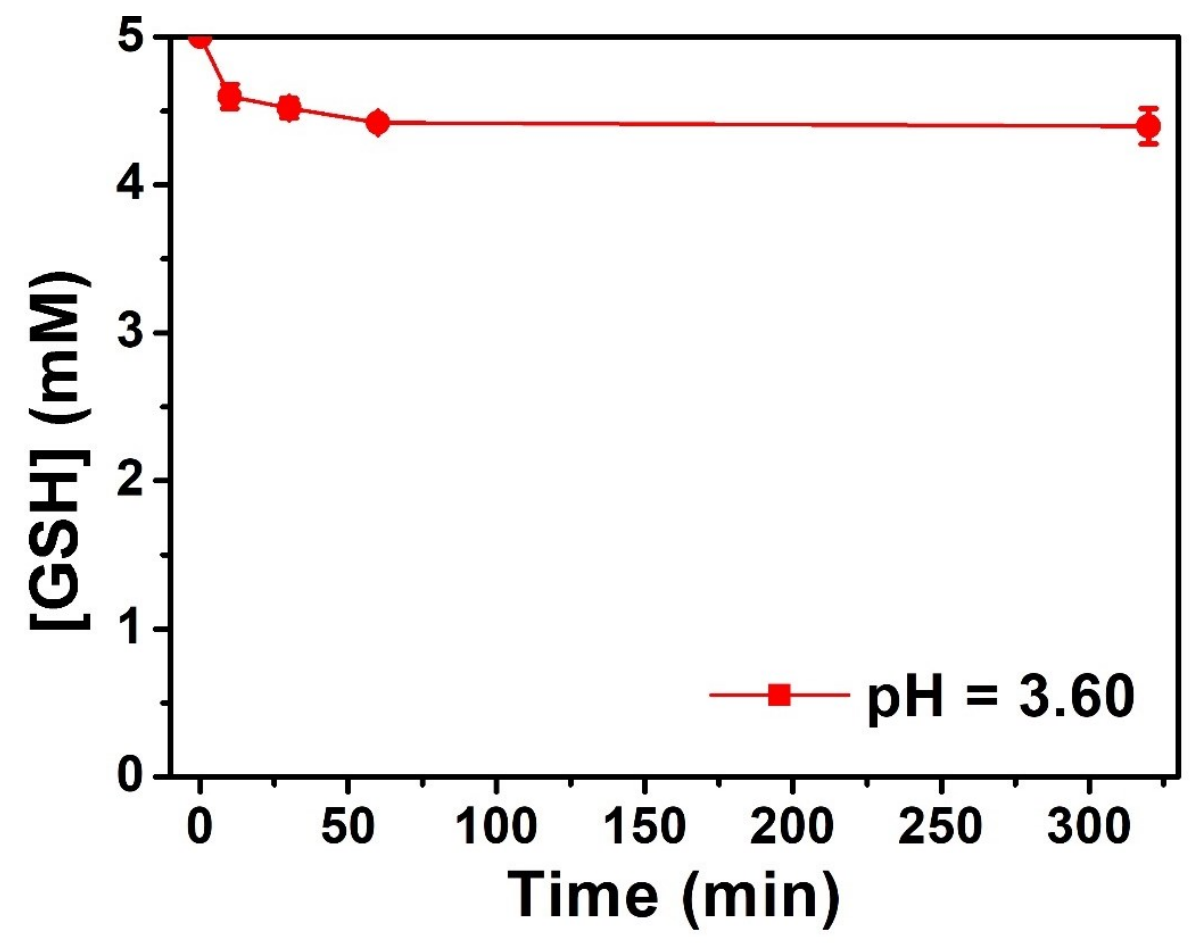

Figure S10. Monitoring of GSH levels at $\mathrm{pH}=3.60$ in the presence of CuFe catalyst, showing a slight decrease in $\mathrm{GSH}$ concentration (in comparison with reaction at $\mathrm{pH}=$ 5.80 or 7.40 ) at early reaction time (320 minutes). Results are in agreement with ${ }^{1} \mathrm{H}-$ NMR/DOSY experiments (Fig. S3a-c) indicating that GSH was present in the reaction after $3 \mathrm{~h}$ of reaction. 


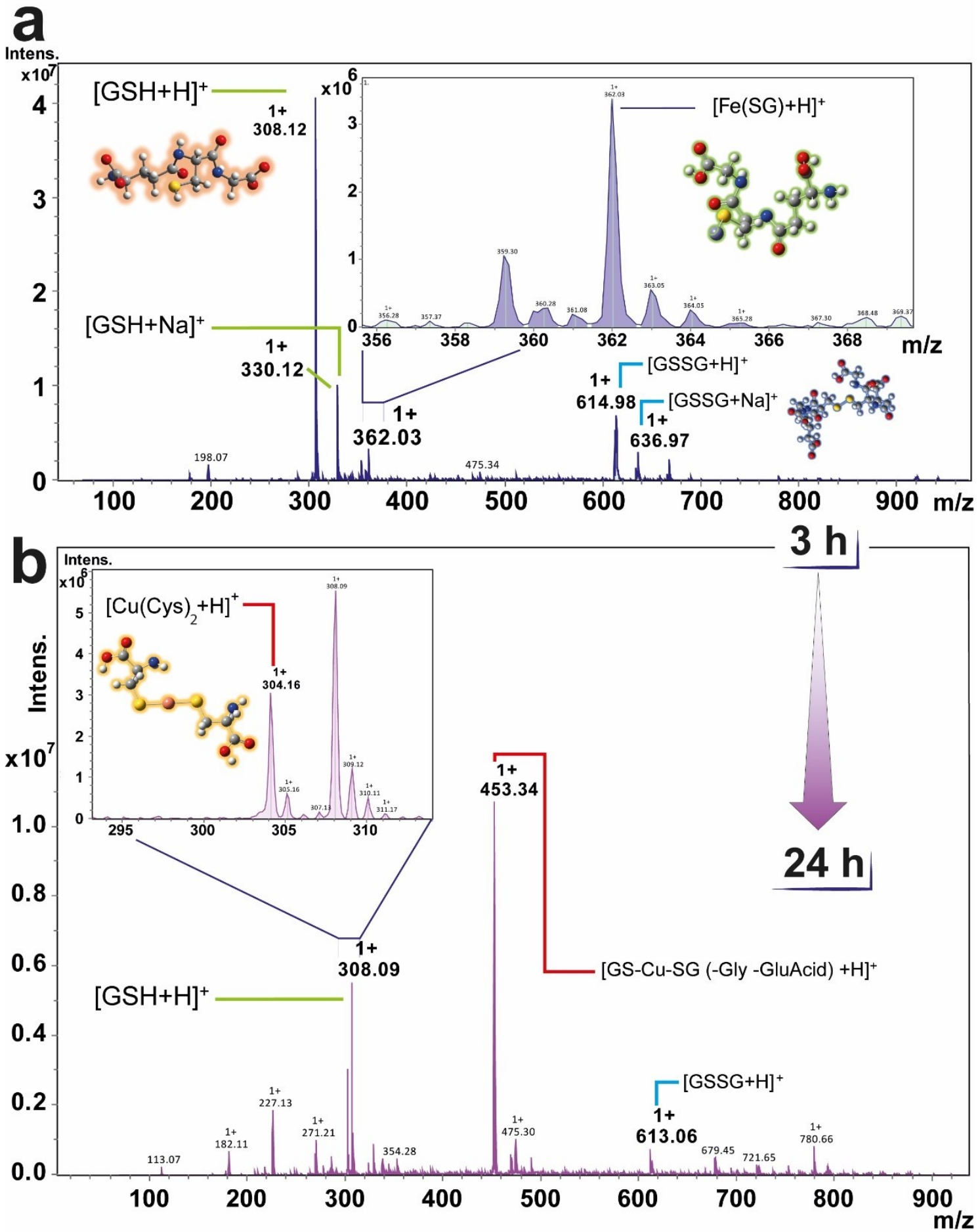

Figure S11. MS-ESI analysis of CuFe+GSH reaction $(\mathrm{pH}=3.60)$ at $(\mathrm{a}) 3 \mathrm{~h}$ and (b) 24 h. $[\mathrm{Fe}(\mathrm{SG})+\mathrm{H}]^{+}$complex formed by Fe leached in the reaction at acidic $\mathrm{pH}$ is found at $\mathrm{m} / \mathrm{z}=362.03$. Remaining $\mathrm{GSH}$ signal $\left(\mathrm{m} / \mathrm{z}=308.19,[\mathrm{GSH}+\mathrm{H}]^{+}\right.$and $\mathrm{m} / \mathrm{z}=330.12$ $[\mathrm{GSH}+\mathrm{Na}]^{+}$) is attributed to slow kinetics of Fe-catalytic oxidation of $\mathrm{GSH}$. Analysis of the reaction at $24 \mathrm{~h}$ reveals the generation of $\left[\mathrm{Cu}(\mathrm{SG})_{2}\right]^{+}$as fragments of $\left[\mathrm{Cu}(\mathrm{cys})_{2}\right]^{+}$ and [Cu(SG)-Gly-GluAcid] appears in the HRMS-ESI at $\mathrm{m} / \mathrm{z}=304$ and 453 , respectively. 


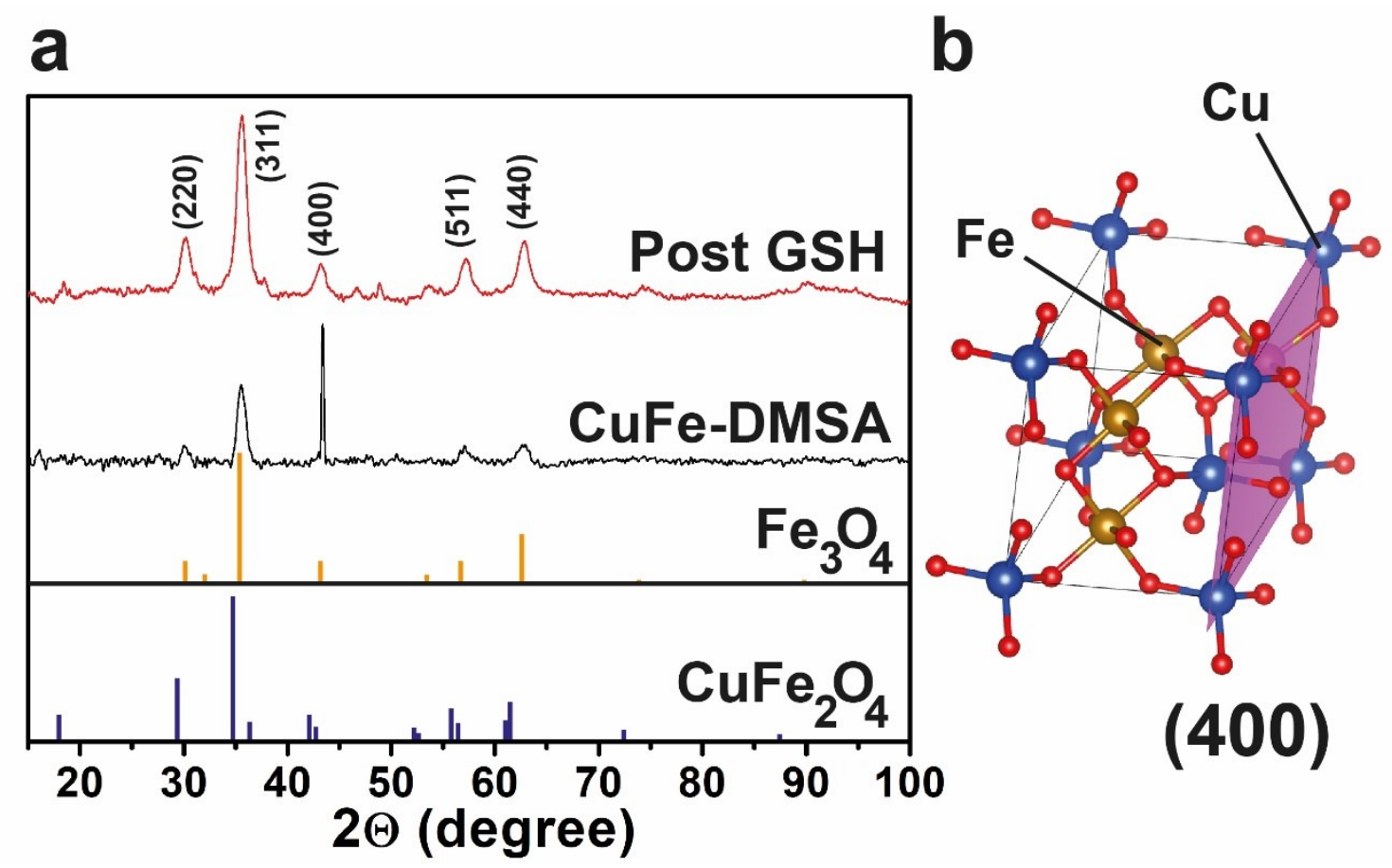

Figure S12. (a) XRD pattern obtained from CuFe-BSA and CuFe-DMSA after reaction with $5 \mathrm{mM}$ of $\mathrm{GSH}$ and (b) Cubic structure of $\mathrm{CuFe}_{2} \mathrm{O}_{4}$ where $\mathrm{Fe}$ and $\mathrm{Cu}$ occupy octahedral and tetrahedral sites, respectively. 


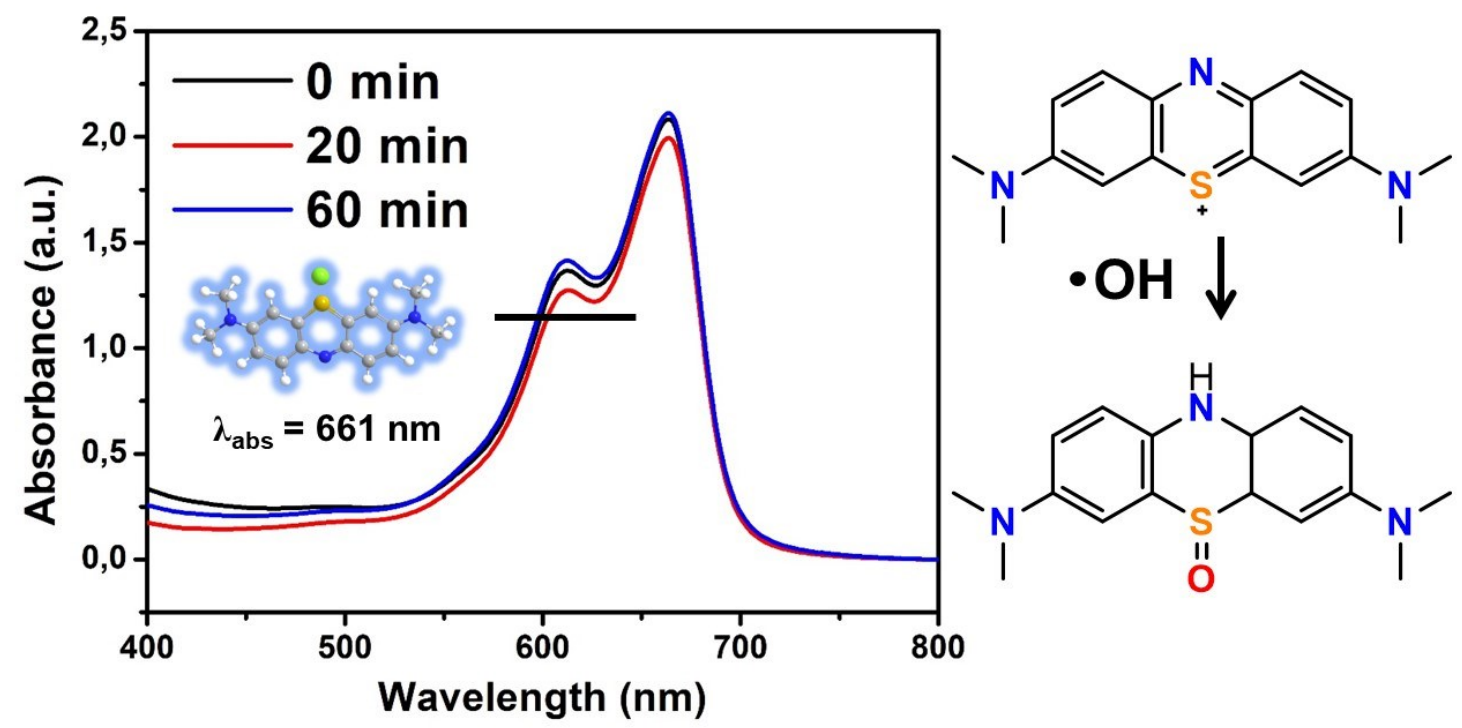

Figure S13. Study of $\mathrm{OH}$ generation from from reaction of Fe-enriched catalyst $(0.1$ $\mathrm{mg} \cdot \mathrm{mL}^{-1}$ ). UV-vis spectra of Methylene Blue at different times (after CuFe incubation with $5 \mathrm{mM} \mathrm{GSH}$ to provoke $\mathrm{Cu}$ release) in the presence of $\mathrm{H}_{2} \mathrm{O}_{2} 1 \mathrm{mM}\left(\mathrm{T}=25^{\circ} \mathrm{C}, \mathrm{pH}=\right.$ 6.5 (adjusted with $\mathrm{CH}_{3} \mathrm{COO}^{-} 0.05 \mathrm{M}$ ). 


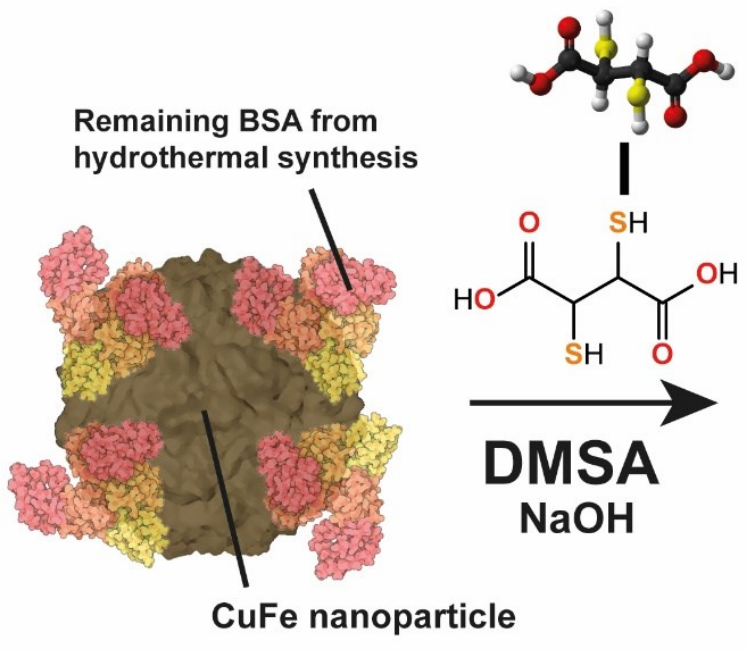

\section{CuFe-BSA}

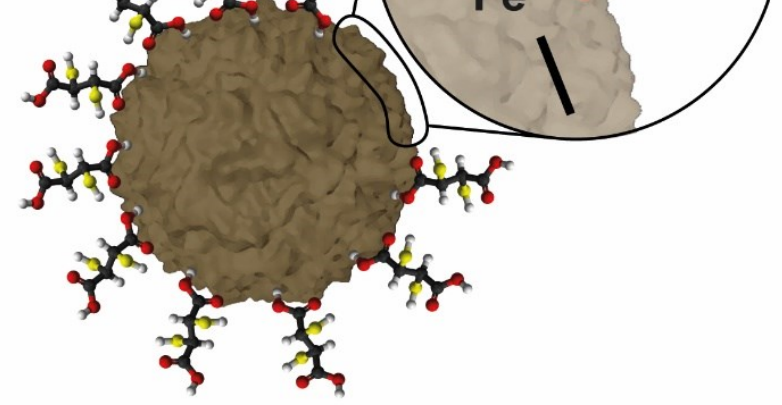

CuFe-DMSA

Figure S14. CuFe-DMSA synthesis route. A ligand exchange process is applied to assynthetized CuFe-BSA nanoparticles to promote the replacement of BSA remaining from the hydrothermal synthesis by DMSA. An alkaline medium is necessary to solubilize DMSA into the aqueous media. Once deprotonated, carboxyl groups from DMSA are able to bind to Fe ${ }^{\text {III }}$ sites in the nanoparticle to enhance the dispersion of the nanoparticles in aqueous media. 

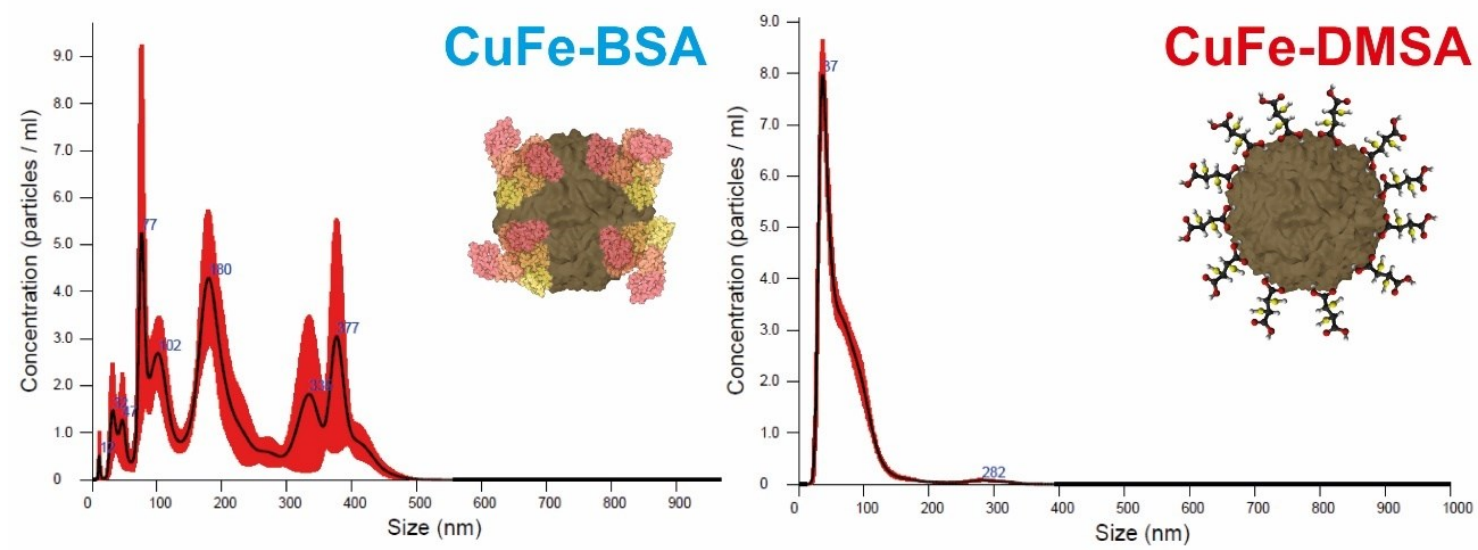

Figure S15. Nanoparticle Tracking Analysis (NTA) of CuFe before (BSA) and after DMSA functionalization, showing the effectiveness of DMSA functionalization to disperse the nanoparticles in aqueous media. 
Table S1. Elemental composition of CuFe surface measured by XPS before exposure to GSH.

\begin{tabular}{ccccc}
\hline \multicolumn{5}{c}{ Binding Energy (eV) } \\
\hline Cu 2p & Fe 2p & O 1s & N 1s & C 1S \\
\hline 932.6 & 710.8 & 530.4 & 400.2 & 285.0 \\
$7.80 \%$ & $18.74 \%$ & $40.15 \%$ & $0.81 \%$ & $32.47 \%$
\end{tabular}

Table S2. Elemental composition of CuFe surface measured by XPS after exposure to GSH.

\begin{tabular}{ccccc}
\hline \multicolumn{5}{c}{ Binding Energy (eV) } \\
\hline Cu 2p & Fe 2p & O 1s & N 1s & C 1S \\
\hline 932.2 & 711.2 & 530.3 & 400.1 & 285.0 \\
$0.28 \%$ & $21.00 \%$ & $44.24 \%$ & $2.52 \%$ & $31.96 \%$
\end{tabular}

Table S3. XPS quantification of the different $\mathrm{Fe}$ and $\mathrm{Cu}$ species present on the catalyst surface before exposure to GSH.

\begin{tabular}{cc|cc}
\hline \multicolumn{2}{c|}{$\mathrm{Fe}^{2+}$} & \multicolumn{2}{c}{$\mathrm{Fe}^{3+}$} \\
\hline $2 \mathrm{p} 3 / 2$ & $\mathrm{~S} . \mathrm{O}$ & $2 \mathrm{p} 3 / 2$ & $\mathrm{~S} . \mathrm{O}$ \\
\hline 710.6 & 714.0 & 712.1 & 718.4 \\
$40 \%$ & - & $60 \%$ & - \\
\hline $\mathrm{Cu}{ }^{0 /+}$ & & & \\
\hline $2 \mathrm{p} 3 / 2$ & $2 \mathrm{p} 3 / 2$ & $\mathrm{Cu}^{2+}$ & $\mathrm{S} .0 .1$ \\
\hline 932.6 & 934.3 & 941.2 & 944.2 \\
$17 \%$ & $83 \%$ & - & -
\end{tabular}

Table S4. XPS quantification of the different Fe and $\mathrm{Cu}$ species present on the catalyst surface after exposure to GSH.

\begin{tabular}{cc|cc}
\hline \multicolumn{2}{c|}{$\mathrm{Fe}^{2+}$} & \multicolumn{2}{c}{$\mathrm{Fe}^{3+}$} \\
\hline $2 \mathrm{p} 3 / 2$ & $\mathrm{~S} . \mathrm{O}$ & $2 \mathrm{p} 3 / 2$ & $\mathrm{~S} . \mathrm{O}$ \\
\hline 710.9 & 713.7 & 711.0 & 718.6 \\
$28.5 \%$ & - & $71.5 \%$ & - \\
\hline $\mathrm{Cu}^{0 /+}$ & & $\mathrm{Cu}^{2+}$ & \\
\hline $2 \mathrm{p} 3 / 2$ & $2 \mathrm{p} 3 / 2$ & $\mathrm{~S} .0 .1$ & $\mathrm{~S} .0 .2$ \\
\hline 932.7 & 934.5 & 941.2 & 943.7 \\
$59 \%$ & $41 \%$ & &
\end{tabular}


Table S5. GSH standards composition employed to analyse GSH-catalytic experiments.

\begin{tabular}{cccc}
{$[\mathrm{GSH}](\mathrm{ppm})$} & $\begin{array}{c}\mathrm{V}_{\mathrm{GSH}} 100 \mathrm{ppm} \\
(\mu \mathrm{L})\end{array}$ & $\begin{array}{c}\mathrm{V}_{\text {DTNB }} 1 \mathrm{mM} \\
(\mu \mathrm{L})\end{array}$ & $\begin{array}{c}\mathrm{V}_{\text {TRIS }} 0.01 \mathrm{M} \\
(\mu \mathrm{L})\end{array}$ \\
\hline 2.5 & 25 & 100 & 875 \\
5.0 & 50 & 100 & 850 \\
10 & 100 & 100 & 800 \\
20 & 200 & 100 & 700 \\
40 & 400 & 100 & 500
\end{tabular}

\section{S12. References}

1 Liu, Y. et al. All-in-One Theranostic Nanoagent with Enhanced Reactive Oxygen Species Generation and Modulating Tumor Microenvironment Ability for Effective Tumor Eradication. ACS Nano 12, 4886-4893, doi:10.1021/acsnano.8b01893 (2018).

2 Zhang, J. et al. Copper ferrite heterojunction coatings empower polyetheretherketone implant with multi-modal bactericidal functions and boosted osteogenicity through synergistic photo/Fenton-therapy. Chemical Engineering Journal 422, 130094, doi:https://doi.org/10.1016/j.cej.2021.130094 (2021).

3 Hai, C. et al. Roles of ethylene glycol solvent and polymers in preparing uniformly distributed MgO nanoparticles. Journal of Asian Ceramic Societies 5, 176-182, doi:10.1016/j.jascer.2017.04.004 (2017).

4 Behzadi, S. et al. Cellular uptake of nanoparticles: journey inside the cell. Chemical Society Reviews 46, 4218-4244, doi:10.1039/C6CS00636A (2017).

5 Miguel-Sancho, N. et al. Development of Stable, Water-Dispersible, and Biofunctionalizable Superparamagnetic Iron Oxide Nanoparticles. Chemistry of Materials 23, 2795-2802, doi:10.1021/cm1036452 (2011). 